\title{
Actions of NCX, PMCA and SERCA on Short-Term Facilitation and Maintenance of Transmission in Nerve Terminals
}

\author{
M. Desai-Shah and R.L. Cooper*
}

Department of Biology, University of Kentucky, Lexington, KY-40506-0225, USA

\begin{abstract}
Residual $\mathrm{Ca}^{2+}$ can accumulate in the nerve terminal during repetitive stimulation; thus, the basis for short-term facilitation (STF). The plasmalemmal $\mathrm{Na}^{+} / \mathrm{Ca}^{2+}$ exchanger [NCX], the $\mathrm{Ca}^{2+}$-ATPase (PMCA) and the sarcoplasmic/endoplasmic reticulum $\mathrm{Ca}^{2+}$-ATPase (SERCA) on the endoplasmic reticulum are three important $\mathrm{Ca}^{2+}$ regulatory processes in controlling $\left[\mathrm{Ca}^{2+}\right]_{\text {. }}$. The role of these $\left[\mathrm{Ca}^{2+}\right]_{\mathrm{i}}$ regulators in the development and maintenance of STF was addressed at the neuromuscular junction. When the NCX is compromised by reduced $\left[\mathrm{Na}^{+}\right]_{0}$, the EPSP amplitudes decrease, but with KB-R7943 (a reverse blocker of NCX) the amplitude increases. Compromising the PMCA with $\mathrm{pH} 8.8$ produces an increase in EPSP amplitudes, but treatments with carboxyeosin (a blocker of PMCA) produced mixed results. Blocking the SERCA increases EPSP amplitudes. Facilitation was only slighted altered in some conditions with these manipulations. The results support the view that release is not saturated during a plateau phase of STF since the terminal is able to reach a new plateau with higher stimulation frequency or an altered $\left[\mathrm{Ca}^{2+}\right]$. Multiple approaches in compromising the NCX and PMCA are presented. These findings are significant because there is a rapid alteration in transmission when compromising $\mathrm{Ca}^{2+}$ extrusion mechanisms during STF.
\end{abstract}

Key words: Facilitation, calcium, synapse, homeostatic

\section{INTRODUCTION}

Chemical synaptic transmission is well established, from insects to mammals, to be dependent on the extracellular calcium levels [1-3]. A power relationship of 3 to 5 exists for the influence of calcium on transmitter release for a number of preparations [4,5]. Transmission is generally enhanced with an increase in $\left[\mathrm{Ca}^{2+}\right]_{\mathrm{i}}$ in the presynaptic terminal. In addition, residual $\mathrm{Ca}^{2+}$ due to previous evoked activity can accumulate which is the basis for short-term facilitation (STF) [6-8]. Pumps and the sodium/calcium exchanger (NCX) can rapidly regulate $\left[\mathrm{Ca}^{2+}\right]_{i}$; thus, having an effect on the rise and decay of $\left[\mathrm{Ca}^{2+}\right]_{\mathrm{i}}$ and on the dynamics of residual $\left[\mathrm{Ca}^{2+}\right]_{\mathrm{i}}[9,10]$. Calcium binding proteins also alters the time course of residual $\left[\mathrm{Ca}^{2+}\right]_{\mathrm{i}}[7,11]$.

The release of $\mathrm{Ca}^{2+}$ from internal stores such as smooth endoplasmic reticulum (ER), mitochondria, Golgi apparatus, synaptic vesicles, and calcium bound to molecules, such as calmodulin [12], can account for background $\left[\mathrm{Ca}^{2+}\right]_{\mathrm{i}}$ that might well play a role with sustained stimulation frequencies. Release of $\mathrm{Ca}^{2+}$ from ER can be regulated by inositol 1,4,5-trisphosphate (IP3) [13-15] and possible other mediators: activation of ryanodine receptors, cyclic adenosine diphosphate-ribose (cADPR), NAADP, ryanodine, caffeine, or $\mathrm{Ca}^{2+}$ itself (the so-called $\mathrm{Ca}^{2+}$-induced $\mathrm{Ca}^{2+}$ release or CICR) [16-22]. Since activation of ryanodine receptors within presynaptic nerve terminals is known to alter evoked transmitter release [23], this would suggest that there is an uptake into the ER by the sarcoplasmic/

*Address correspondence to this author at the 675 Rose St., Dept of Biology, Univ. of KY, Lexington, KY. 40506-0225, USA. Tel.: 859-5597600 (cell); Fax: 859-257-5950; E-mail: RLCOOP1@email.uky.edu endoplasmic reticulum $\mathrm{Ca}^{2+}$-ATPase (SERCA). Dropic et al., [18] also demonstrated that adenophostin-A (a stable analog of IP3) and caffeine enhanced transmitter release at the crayfish neuromuscular junction which unloads $\mathrm{Ca}^{2+}$ from the ER. This general phenomena is likely a commonality among motor nerve terminals since electron microscope spectroscopic imaging in frog motor nerve terminals revealed the presence of $\mathrm{Ca}^{2+}$-loaded smooth ER, mitochondria, SER and synaptic vesicles [24].

The NCX, PMCA and SERCA are all well established to have rapid effects on synaptic transmission and the associated facilitation and/or depression, for particular synaptic preparations, when their activity is inhibited [25$28]$. $\left[\mathrm{Ca}^{2+}\right]_{\mathrm{i}}$ during stimulation is dependent on the electrochemical driving gradients on the voltage-dependent $\mathrm{Ca}^{2+}$ channels $\left(\mathrm{Ca}^{2+} \mathrm{v}\right)$ but also on the distribution and density of these channels as well as others (i.e., $\mathrm{K}_{\mathrm{Ca}}$ channel) that regulate depolarization of the membrane [29]. Evidence suggests that within synapses the $\mathrm{Ca}^{2+} \mathrm{v}$ channels are localized within an area around the "active zone". They are recruited for transmission when stimulation is sufficient. Depending on the number of AZs within a synapse and the number of synapses within a length of nerve terminal, the amount of $\mathrm{Ca}^{2+}$ entry within the terminal during depolarization may be restricted locally or more diffuse. Structural differences of synapses such as the size of the AZ (i.e. the length of the dense bar) and spacing between AZs on the synapse can influence the resulting $\left[\mathrm{Ca}^{2+}\right]_{i}$, thus regulating vesicular release [7,30-32]. The synaptic complexity at the crayfish NMJ has been fairly well described by direct structure-function studies with serial electron micrographic reconstruction on physiologically recorded terminals [30,32-37]. Furthering knowledge in 
understanding the $\mathrm{Ca}^{2+}$ regulation, during STF, allows one to build on this past knowledge in synaptic structure and efficacy to model the terminal in relation to vesicle kinetics and spatial organization of proteins and organelles that could have an impact on STF.

With repetitive stimulation in terminals which do not rapidly depress, such as for the crayfish tonic opener motor neuron, STF [8] as well as LTF [38] can be induced. With short pulse trains, the excitatory postsynaptic potentials (EPSP) may reach a plateau in their amplitude [39,40]; however, with a higher frequency of stimulation a new plateau in the EPSP amplitude will be obtained. Even though the electrochemical driving gradient for the EPSP is still sufficient to result in larger potentials, a plateau in the EPSP amplitude occurs. This is because the number of vesicles fusing is regulated but not limiting. The $\left[\mathrm{Ca}^{2+}\right]_{i}$ increase during the stimulation train, but it is presumed that equilibrium is reached with the influx, buffering and exchange mechanisms to result in a steady state of vesicle docking and fusion [2]. This suggests vesicles rapidly refill and/or that they are replenished from a reserve pool as not to deplete filled vesicles for a readily releasable pool. With a transition to a higher stimulation frequency it is likely a new equilibrium is established at a higher $\left[\mathrm{Ca}^{2+}\right]_{\mathrm{i}}$. The higher stimulation rate also results in a faster rise in $\left[\mathrm{Ca}^{2+}\right]_{\text {i }}$, thus resulting in a faster rise of the EPSPs to the plateau level. This phenomenon may in part be due a lingering residual $\left[\mathrm{Ca}^{2+}\right]_{\mathrm{i}}$ or even to an increase in $\left[\mathrm{Ca}^{2+}\right]_{\mathrm{i}}$ induced enhancement by the NCX working in reverse due to the high influx through the evoked $\mathrm{Na}^{+}{ }_{\mathrm{V}}$ channels, thus resulting in a faster steady state process. One might assume, a limitation in the number of vesicles that can be released at the AZs within a short period accounts for a steady state. Such an anatomical limitation in the number of active zones may also be the rational for higher-output terminals associated with phasic motor nerves terminals which do not facilitate as much as lower-output tonic motor nerve terminals [41,42]. However, a limitation in vesicular docking does not appear to be a factor for 20 pulse trains of 20,40 and $60 \mathrm{~Hz}$ stimulation rates since application of the neuromodulator 5 -HT produces more vesicles to fuse presynaptically (i.e., an increased probability) during these evoked stimulus trains [43].

The purpose of this study was to determine if the release process during the plateau phase of STF is in part balanced by the NCX, PMCA and SERCA. In addition, we were interested to know to what extent these proteins function to induce STF. Since the crayfish is not amenable to genetic manipulation, as other model organisms, such as the fruit fly, we used pharmacological and ionic manipulations to compromise the function of these three $\mathrm{Ca}^{2+}$ regulatory proteins. We did perform a comparable study at the Drosophila NMJ earlier [44]. Herein we compared different approaches to target the same protein to address if the approaches are complimentary to each other. One approach in dampening the function of the NCX is by reducing the driving gradient of $\mathrm{Na}^{+}$into the terminals by using a lower $\left[\mathrm{Na}^{+}\right]_{\mathrm{o}}$; however, we were concerned that this could have an impact on the shape of the action potential which would indirectly effect $\mathrm{Ca}^{2+}{ }_{v}$ channels. To address this issue, we measured, with intracellular electrodes, the shape of the action potential in the pre-terminal axons before and during $\left[\mathrm{Na}^{+}\right]_{\mathrm{o}}$ manipulations. Previous experiments by Hodgkin and
Katz [45] in the giant axon of the squid have shown that

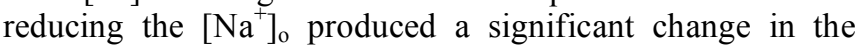
amplitude of the action potentials while alterations in the resting membrane potential was comparatively small. These experiments were done in the squid, where the $\left[\mathrm{Na}^{+}\right]_{0}$ is more than twice that for the fresh water crayfish, so the results cannot be extrapolated directly to the crayfish without being first tested. The crayfish opener NMJ serves as a good model for synaptic physiology since the postsynaptic responses are graded, shows pronounced STF, and the amplitude of the EPSPs are directly related to the presynaptic efficacy.

\section{MATERIALS AND METHODS}

\section{General}

All experiments were performed using the first and second walking legs of freshly obtained crayfish, Procambarus clarkii, measuring 6-10 $\mathrm{cm}$ in body length (Atchafalaya Biological Supply Co., Raceland, LA). Animals were housed individually in an aquatic facility and fed dried fish food. Dissected preparations were maintained in crayfish saline, a modified Van Harreveld's solution (in $\mathrm{mM}$ : $205 \mathrm{NaCl} ; \quad 5.3 \mathrm{KCl} ; \quad 13.5 \quad \mathrm{CaCl}_{2} .2 \mathrm{H}_{2} \mathrm{O} ; \quad 2.45$ $\mathrm{MgCl}_{2} \cdot 6 \mathrm{H}_{2} \mathrm{O} ; 5$ HEPES adjusted to $\mathrm{pH}$ 7.4). Crayfish were induced to autotomize the first or second walking leg by forcefully pinching at the merus segment. Details of the dissection and equipment used are shown in video format [46].

\section{Chemicals}

All chemicals were obtained from Sigma chemical company (St. Louis, MO) with the exception of thapsigargin and KB-R7943 which were obtained from Tocris (Ellisville, $\mathrm{MO}$ ) and 5,6-carboxyeosin from Marker Gene Technologies Inc. (Eugene, OR).

To reduce the driving force for the NCX a saline with a reduction of $\left[\mathrm{Na}^{+}\right]_{0}$ by two-thirds was used. The $\mathrm{Na}^{+}$was substituted by choline chloride to balance osmolarity. In order to inhibit the PMCA, the $\mathrm{pH}$ of saline is raised to 8.8 from its normal value of 7.4. Thereafter, in order to study a compromised NCX and PMCA, the concentration of $\mathrm{Na}^{+}$in the saline is reduced by $2 / 3^{\text {rds }}$ and $\mathrm{pH}$ held at 8.8 . Reduction in function of the SERCA was approached by exposure to thapsigargin (TG) $(10 \mu \mathrm{M})$ for 10 minutes while providing stimulus pulse trains [47]. We also compared a reduction in $2 / 3^{\text {rds }}\left[\mathrm{Na}^{+}\right]_{0}$ to the reverse NCX blocker ( KB-R7943; 40 $\mu \mathrm{M})$ for any potential effects. KB-R7943 is known to block the influx, but not the efflux, of $\mathrm{Ca}^{2+}$ through the NCX in rat myocytes $(5 \mu \mathrm{mol} / \mathrm{L}$ within 15 seconds, [48]). To examine the difference of inhibiting the PMCA by pH8.8 and a pharmacological approach carboxyeosin (CE) was used. It was shown that $5 \mu \mathrm{M}$ is sufficient to inhibit PMCA in rats and in guinea pigs [49]. Therefore, we used this concentration and incubated the preparation for 10 minutes.

\section{Physiology}

To elicit an evoked response, the excitatory axon was selectively stimulated by placing a branch of the leg nerve (from the merus segment) into a suction electrode connected to a Grass stimulator [50]. STF was obtained by giving a 
Table 1. Composition of Saline with Reduced $\mathrm{Na}^{+}$and Compensated with Choline Chloride

\begin{tabular}{|c|c|c|c|c|c|c|}
\hline & $\begin{array}{c}\mathbf{1 0 0 \%} \text { Na+ } \\
\text { (Normal Saline) }\end{array}$ & $\mathbf{8 0 \% ~ N a +}$ & $\mathbf{6 6 . 6 6 \%} \mathbf{N a}+$ & $\mathbf{5 0 \%} \mathbf{N a}+$ & $\mathbf{3 3 . 3 3 \%} \mathbf{N a}+$ & $\mathbf{2 0 \%} \mathbf{N a}+$ \\
\hline \hline NaCl & $205 \mathrm{mM}$ & $164 \mathrm{mM}$ & $136.65 \mathrm{mM}$ & $102.5 \mathrm{mM}$ & $68.32 \mathrm{mM}$ & $41 \mathrm{mM}$ \\
\hline $\begin{array}{c}\text { Choline } \\
\text { Chloride }\end{array}$ & NA & $41 \mathrm{mM}$ & $68.3 \mathrm{mM}$ & $102.5 \mathrm{mM}$ & $136.53 \mathrm{mM}$ & $164 \mathrm{mM}$ \\
\hline
\end{tabular}

train of 10 or 20 pulses at 10 or 20 second intervals, respectively, to the excitatory nerve. The frequency of stimulation within the train varied depending on the paradigm $(20,40,60$ and/or $80 \mathrm{~Hz})$. Intracellular EPSP recordings were performed by standard procedures [36,40,51,52].

In order to examine if the reduced $\left[\mathrm{Na}^{+}\right]_{\mathrm{o}}$ had an effect on the shape of the presynaptic action potential, the preterminal of the excitatory axon in the walking leg opener muscle was impaled with sharp intracellular electrode filled with $3 \mathrm{M}$ $\mathrm{KCl}$. The neuromuscular junctions were exposed in situ and bathed in a physiological saline. The motor nerve, in the merus segment, was stimulated by placing it into a suction electrode which was connected to a stimulator. Stimulations were given at a frequency starting from $0.5 \mathrm{~Hz}$ and if the recording started in normal saline with the stimulation just slightly greater than threshold of activation. The stimulation intensity had to be increased as the $\left[\mathrm{Na}^{+}\right]_{\mathrm{o}}$ was reduced. The responses were obtained at a $20 \mathrm{KHz}$ acquisition rate. Initially the preparation was maintained in normal crayfish saline and stimulated. After every 200 stimulations (delivered at $0.5 \mathrm{~Hz}$ ) the external saline was replaced by one with a different $\left[\mathrm{Na}^{+}\right]_{0}$. Six salines with reduced $\mathrm{Na}^{+}$ concentrations from the normal saline were used (see Table 1). When $\mathrm{Na}^{+}$was reduced, the osmolarity was maintained by replacing it with choline chloride. The six different salines with the amounts of $\mathrm{NaCl}$ and choline chloride used for each are shown in Table 1. An agar bridge (1.5\% agar in normal crayfish saline) was used to keep the action potential amplitudes from fluctuating when the saline was changed. Electrical signals were recorded to a on-line Power Mac 9500 via a MacLab/4s interface.

\section{Analysis}

To index facilitation, the ratio in the peak amplitude of the EPSP for one of the preceding pulses from the last one within the stimulus train was used. A unitary value of 1 was subtracted from the ratio to provide a facilitation index (FI). The subtraction of one ensures that if no facilitation is present (i.e., the amplitudes of the responses are the same), FI will be zero. In addition, the amplitudes of the plateau EPSPs were compared within preparations at different stimulation frequencies by procedures previously described [40]. Statistics employed were either the Student's t-test or a Wilcoxon paired rank sum test (a non-parametric test).

\section{RESULTS}

\section{Opener Muscle and STF}

The opener muscle is divided in three general regions: distal, central and proximal. Even though the entire open muscle is innervated by a single motor neuron, the NMJs are structurally different and have regional specific differences in synaptic efficacy in these three general regions $[30,36]$. The muscle fiber phenotype type has also been shown to be different in these regions $[53,54]$. For these reasons, the most distal fibers were used (Fig. 1A). The STF induced by a series of pulses delivered at different frequencies to the opener motor neuron produces a train of EPSPs that initially facilitate and then reach a quasi-stable state which produces a plateau in the amplitude of the responses. The opener muscle preparation and the responses for 20 stimulus pulses delivered at 20,40, and $60 \mathrm{~Hz}$ stimulation trains are shown in Fig. (1B) and 30 pulses at $40 \mathrm{~Hz}$ in Fig. (1C). The rate of the increase in the EPSP amplitude and the amplitude of the plateau increases as the stimulation rate increases.

Given the amplitudes of the EPSPs are fairly consistent after the $20^{\text {th }}$ pulse in the $20 \mathrm{~Hz}$ stimulation paradigm one might predict that the rate of vesicle recycling might have reached a maximum; however stimulating at a higher frequency the EPSPs amplitudes increase and reach a new plateau level (Fig. 1B, C). Thus, the rate of vesicle recycling likely increases during the onset of STF which is followed by a steady state vesicle recycling during the plateau of the amplitudes.

The changes in the plateau level in the EPSP amplitude with frequency of stimulation is even more pronounced when the bathing saline is switched to one containing $2 / 3^{\text {rd }}$ $\left[\mathrm{Na}^{+}\right]_{\mathrm{o}}$. The depression in the amplitudes is substantial for all the amplitudes within the train. However, only subsets of the EPSPs are analyzed for quantitative purposes (i.e., $1^{\text {st }}, 5^{\text {th }}$, $10^{\text {th }}, 15^{\text {th }}, 20^{\text {th }}, 25^{\text {th }}$ and $30^{\text {th }}$ events). The change in the EPSP amplitudes for each preparation was decreased in 8 out of 8 preparations for all EPSP amplitudes measured $(\mathrm{P}<0.05$, Wilcoxon rank-sum test). In comparing the responses among preparations a percent change from saline exposure to a reduced NCX state was determined. A percent is used since the absolute EPSP amplitudes varied among preparations. The means in the percent differences for the various events within the train were decreased (Fig. 2; $\mathrm{P}<0.05$, Student's paired $t$-test).

The rate of reaching a plateau response is indicated by the facilitation index taken at various EPSPs within the train (Fig. 3A). Also the facilitation index suggests that the response reaches a plateau by about the $10^{\text {th }}$ event in normal $\left[\mathrm{Na}^{+}\right]_{\mathrm{o}}$ and with choline chloride containing saline. Thus, the effect of reducing the NCX results in an alteration early in the initiation of STF but not throughout the train. Since there is substantial variation in the FI for A30/A5, the individual preparations are compared for their absolute change (Fig. 3B). Here 7 out of 8 preparations increased in FI with the reduced $\left[\mathrm{Na}^{+}\right]_{\mathrm{o}}$. To further compare subtleties in the FI, a percent change in the various FI values is shown (Fig. 3C). No significant differences are present. 




Fig. (1). (A) The schematic of the opener muscle in the crayfish walking leg in which the distal muscle fibers were recorded with an intracellular electrode (black arrow). (B) EPSPs in response to a train of 20 stimulation pulses given at three different frequencies 20,40 and $60 \mathrm{~Hz}$ in normal crayfish saline. (C) The measurement in the amplitudes of the EPSPs was obtained by the difference in the potential prior to the event to the peak, as shown for the $15^{\text {th }}, 20^{\text {th }}, 25^{\text {th }}$ and $30^{\text {th }}$ events in a $40 \mathrm{~Hz}$ stimulus train.

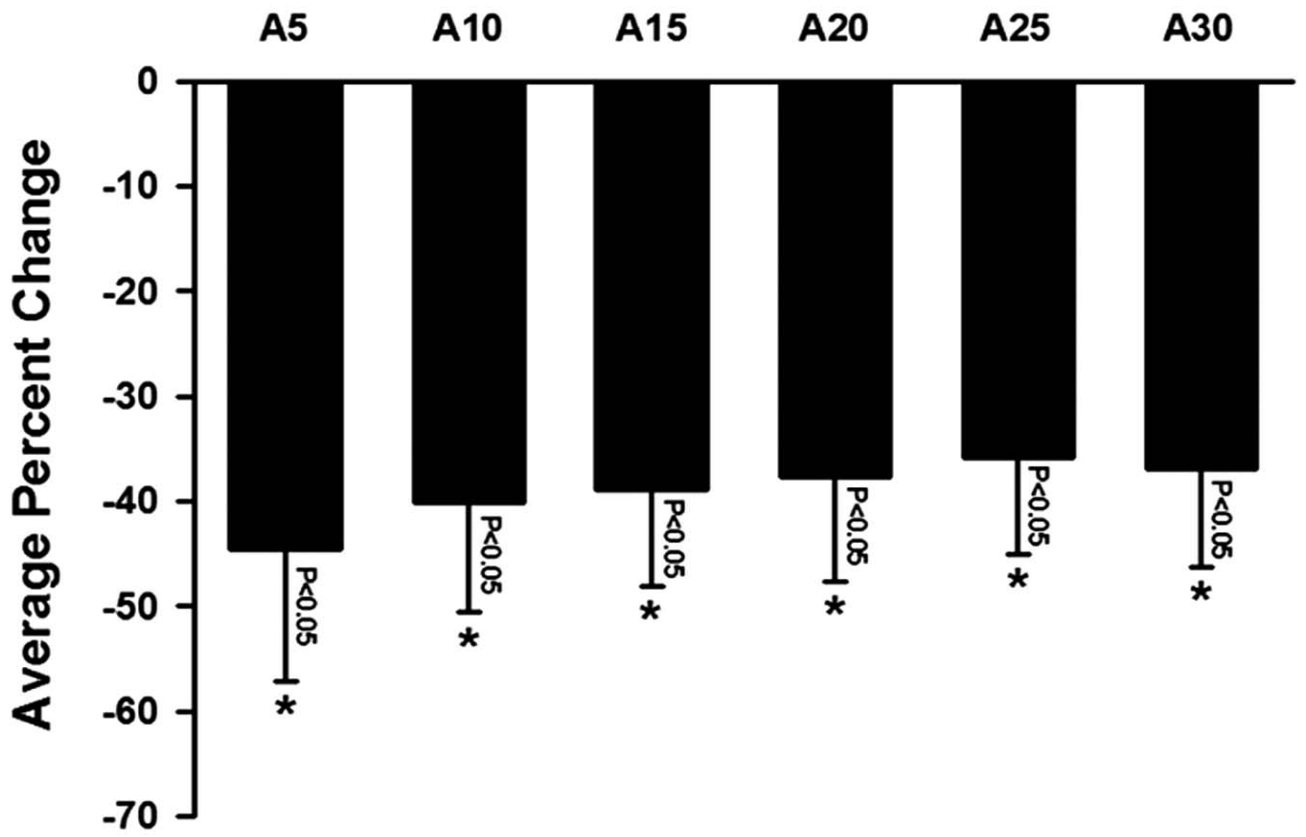

Fig. (2). Composite Fig. (showing percent change in EPSP amplitude before and in the presence of $2 / 3^{\text {rd }}$ reduced $\left[\mathrm{Na}{ }^{+}\right]_{\mathrm{o}}$. (mean $\pm \mathrm{SEM}$; $\mathrm{N}=8$ preparations).

\section{Effects on the Action Potential when Lowering $\left[\mathrm{Na}^{+}\right]_{0}$}

In order to study the influence of decreasing $\left[\mathrm{Na}^{+}\right]_{0}$ on the size of the action potential in the presynaptic neuron, intracellular recordings were carried out on the crayfish tonic motor neuron which innervates the opener muscle in the first walking leg, while changing the $\left[\mathrm{Na}^{+}\right]_{\mathrm{o}}$. The axon (preterminal) was impaled as close to the terminal string of varicosities as possible (Fig. 4A). The action potential was typically in the range of 60 to $80 \mathrm{mV}$ in amplitude with approximately $-74 \mathrm{mV}$ for a resting membrane potential (Fig. 4B). The $\left[\mathrm{Na}^{+}\right]_{\mathrm{o}}$ was decreased successively from $100 \%$ to $20 \%$ in respect to the concentration in normal crayfish 


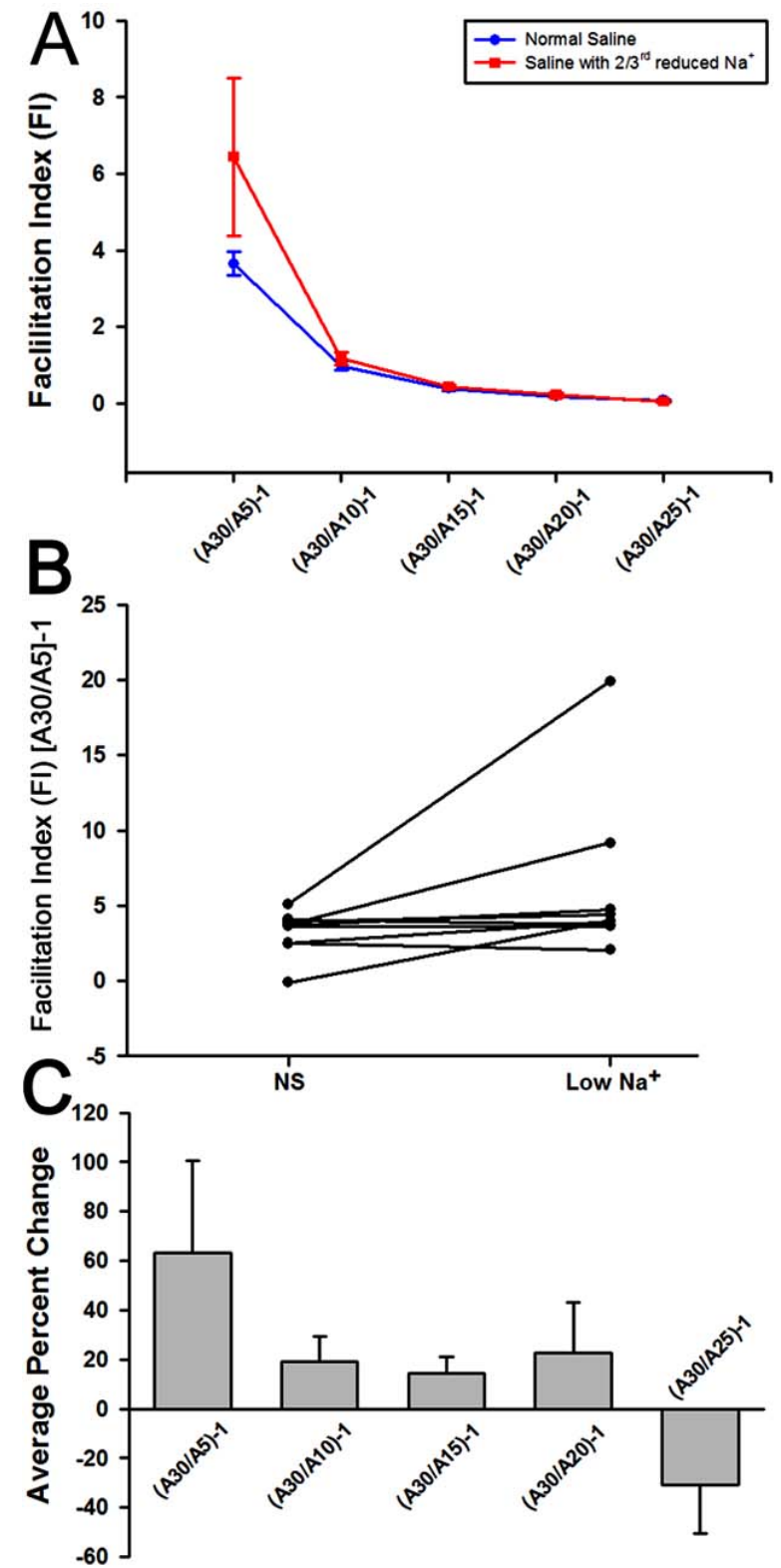

Fig. (3). Facilitation index (FI) in presence of normal and $2 / 3^{\text {rd }}$ reduced (low) $\left[\mathrm{Na}^{+}\right]_{o}$. The FI is compared for a subset of the EPSPs with a 30 pulse train (A). There is only a significant difference in FI among the A30/A5 index (B). (C) Composite Fig. (showing percent change in the facilitation index before and in the presence of $2 / 3^{\text {rd }}$ reduced $\left[\mathrm{Na}^{+}\right]_{0}$. Facilitation Index [(A30/Ax)-1] (where $\mathrm{x}$ is amplitude indicated). (mean $\pm \mathrm{SEM}$; $\mathrm{N}=8$ ).

saline $(205 \mathrm{mM})$. The amplitude was seen to drop on an average by $35 \%$ when the $\left[\mathrm{Na}^{+}\right]_{\mathrm{o}}$ was reduced to $20 \%$. The resting membrane potential (RP) was also measured at each of the different $\left[\mathrm{Na}^{+}\right]_{\mathrm{o}}$. At each $\left[\mathrm{Na}^{+}\right]_{\mathrm{o}}$ the RP only dropped (more negative) by a couple of $\mathrm{mVs}$. From normal $\left[\mathrm{Na}^{+}\right]_{0}$ to $1 / 3^{\text {rd }}$ reduction there was an average decrease of $3.6 \mathrm{mV}$ $(\mathrm{SEM} \pm 0.7)$ and from normal to $2 / 3^{\text {rd }}$ reduced $\left[\mathrm{Na}^{+}\right]_{\mathrm{o}}$ there was an average decrease of $4.0 \mathrm{mV}(\mathrm{SEM} \pm 1.4)$ (see Table 2). Generally the RP became more negative as the $\left[\mathrm{Na}^{+}\right]_{\mathrm{o}}$ was decreased. Although the maximum drop in RP was not consistent for a particular $\left[\mathrm{Na}^{+}\right]_{\mathrm{o}}$ but the RP did drop in 5 out of 5 experiments when the $\left[\mathrm{Na}^{+}\right]_{\mathrm{o}}$ was reduced from the initial concentration $(\mathrm{P}<0.05$, Wilcoxon rank-sum test $)$. There is a significant reduction $(\mathrm{P}<0.05$, One Way Repeated
Measures ANOVA at $2 / 3^{\text {rds }}\left[\mathrm{Na}^{+}\right]_{0}$. This reduction is still above the level to activate the $\mathrm{Ca}^{2+}{ }_{\mathrm{V}}$ channels. The effect of lowering $\left[\mathrm{Na}^{+}\right]_{\mathrm{o}}$ on the amplitude of the action potential is shown for a representative preparation (Fig. 4C). Note the linear drop in amplitude up to the $2 / 3^{\text {rds }}$ reduction. Further reduction in $\left[\mathrm{Na}^{+}\right]_{\mathrm{o}}$ resulted in a drastic drop in the action potential amplitude.

Table 2. Observed and Theoretical Values for the Resting Membrane Potential in the Axon when $\left[\mathrm{Na}^{+}\right]_{0}$ is Varied

\begin{tabular}{|c|c|c|c|c|c|c|}
\hline $\begin{array}{c}\text { \% Na+ in } \\
\text { Saline }\end{array}$ & $\mathbf{1 0 0 \%}$ & $\mathbf{8 0 \%}$ & $\mathbf{6 6 . 6 \%}$ & $\mathbf{5 0 \%}$ & $\mathbf{3 3 . 3 \%}$ & $\mathbf{2 0 \%}$ \\
\hline \hline Theoretical RP & -96 & -97 & -97 & -97 & -97 & -97 \\
\hline Observed RP & -73 & -76 & -78 & -80 & -77 & -77 \\
\hline
\end{tabular}
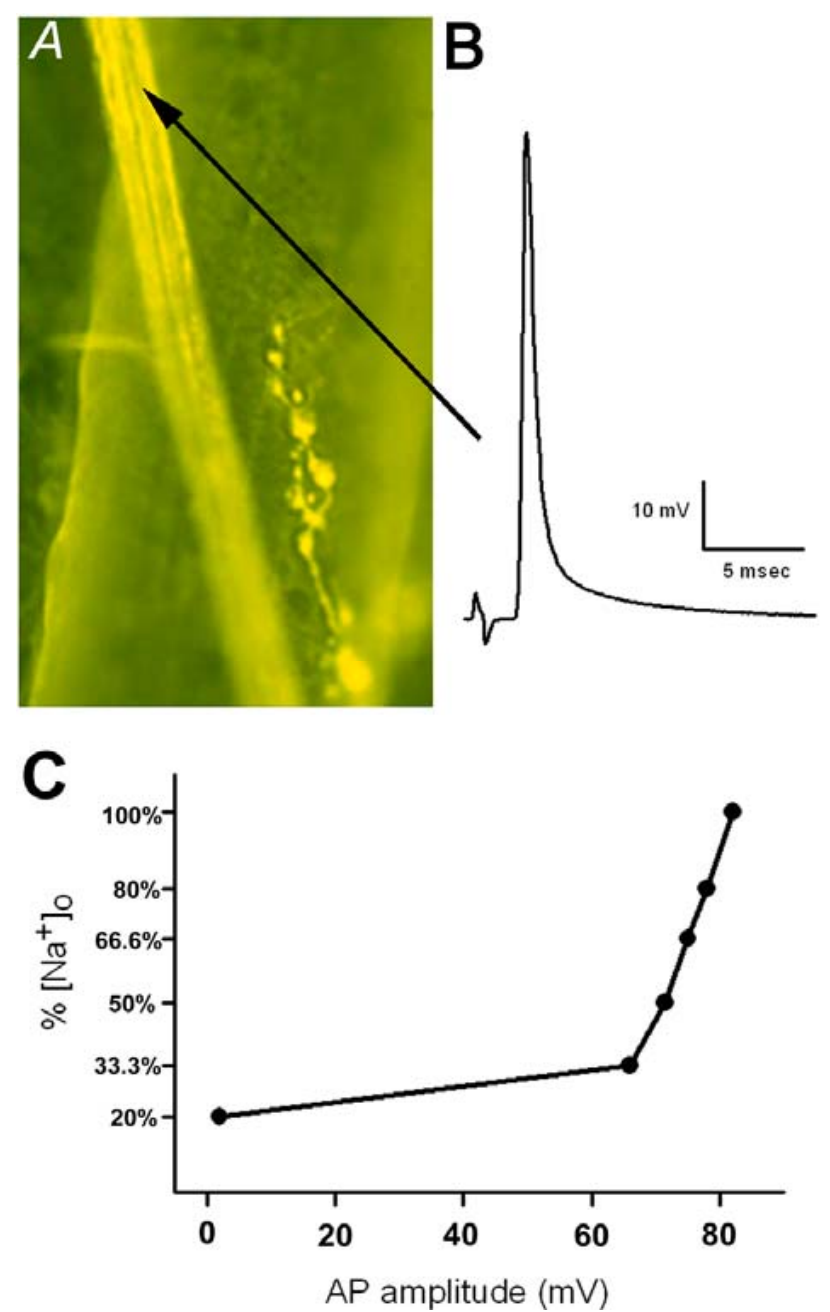

Fig. (4). (A) Light micrograph showing the axon innervating the crayfish walking leg. The preparation was stained using 4,2-DiASP for representative purposes, but the physiological preparations were not stained prior to recording. Note the string of varicosities on the muscle showing that indeed the axon is preterminal. The black arrow indicates the region where the axon is impaled with a recording intracellular electrode. (B) The action potential trace recorded from the excitatory nerve. (C) The change in the amplitude (in $\mathrm{mV}$ ) of the action potential as the $\left[\mathrm{Na}^{+}\right]_{\mathrm{o}}$ is changed for a representative preparation. The $\left[\mathrm{Na}^{+}\right]_{\mathrm{o}}$ is expressed in percent of $\left[\mathrm{Na}^{+}\right]_{\mathrm{o}}$ in normal crayfish saline which is $205 \mathrm{mM}$. 


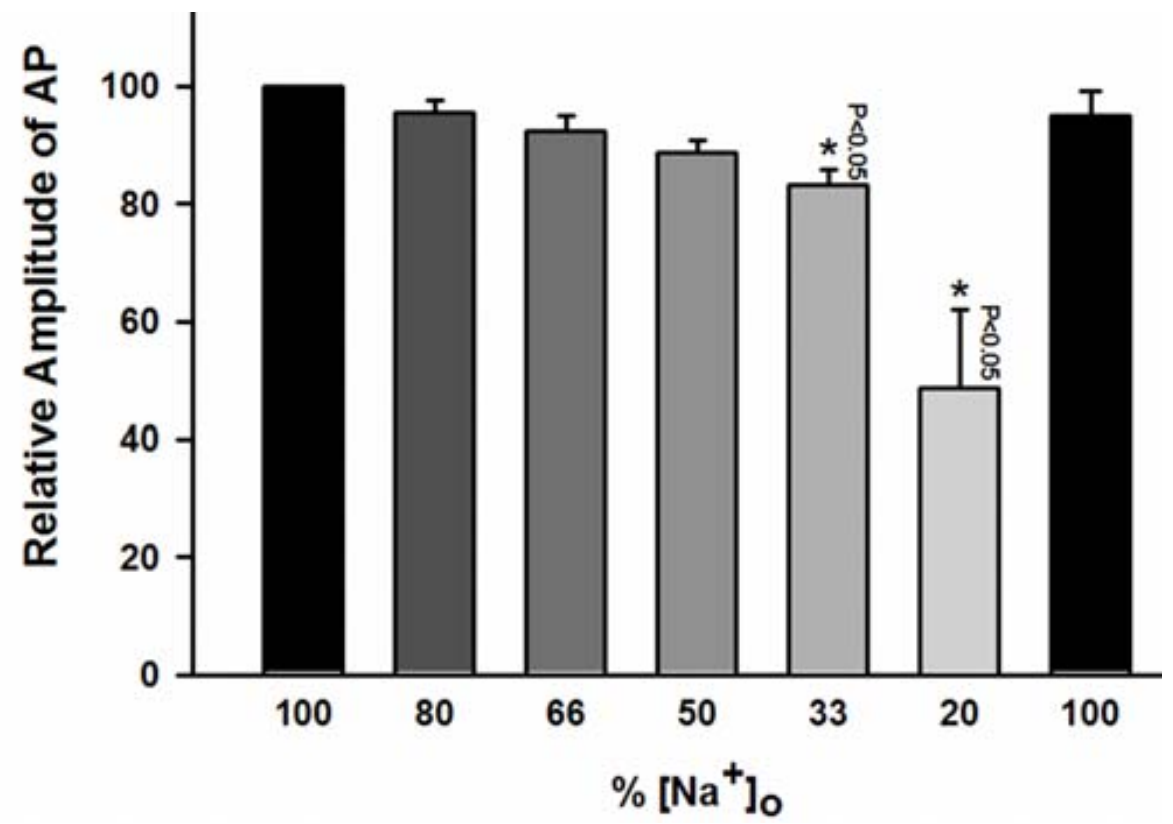

Fig. (5). The average percent change in amplitude of action potentials recorded at different $\left[\mathrm{Na}^{+}\right]_{\mathrm{o}}$. The $\left[\mathrm{Na}^{+}\right]_{\mathrm{o}}$ is expressed in percent of $\left[\mathrm{Na}^{+}\right]_{\mathrm{o}}$ in normal crayfish saline which is $205 \mathrm{mM}$. There is a linear reduction in action potential amplitude as the [ $\left[\mathrm{Na}^{+}\right]_{\mathrm{o}}$ is reduced up to a $2 / 3^{\text {rd }}$ reduction. The change is not significant until the $\left[\mathrm{Na}^{+}\right]_{\mathrm{o}}$ is reduced to $33 \%$ of the original $\left[\mathrm{Na}^{+}\right]_{\mathrm{o}}$. When $\left[\mathrm{Na}^{+}\right]_{\mathrm{o}}$ is reduced by $2 / 3^{\text {rd }} \mathrm{s}$ (to $33 \%$ ) of the original concentration, the action potential amplitude decreases by $\sim 17 \%$. When the $\left[\mathrm{Na}^{+}\right]_{\mathrm{o}}$ is reduced to $20 \%$ of the original concentration the amplitude of the action potential drops to about 50\%. $(P<0.05$, Student's paired $t$-test, $\mathrm{N}=5)$.

\section{Theoretical Calculations}

In order to determine if the reduced $\left[\mathrm{Na}^{+}\right]_{\mathrm{o}}$ follows a predicted decrease in the resting membrane potential a theoretical estimation was made. Previously, ion permeabilities of $\mathrm{Na}^{+}$and $\mathrm{K}^{+}$were determined in the crayfish giant axon by Strickholm and Wallin [55], and the results of the study indicated that when $\left[\mathrm{K}^{+}\right]_{\mathrm{o}}=5.4 \mathrm{mM}$ the value of $\mathrm{P}_{\mathrm{Na}} / \mathrm{P}_{\mathrm{K}}$ is $2.4 \mathrm{X} 10^{-3}$. Moreover, an updated value was determined by Strickholm [56] states $\mathrm{P}_{\mathrm{Na}} / \mathrm{P}_{\mathrm{K}}$ value as $1.44 \mathrm{X}$ $10^{-3}$. Using the values of $\mathrm{P}_{\mathrm{Na}} / \mathrm{P}_{\mathrm{K}}$ one can calculate the change in resting membrane potential with changes in the $\left[\mathrm{Na}^{+}\right]_{\mathrm{o}}$.
These theoretical values were then compared to the experimentally determine values (Table 2 ).

It should be kept in mind that these values for $\mathrm{P}_{\mathrm{Na}} / \mathrm{P}_{\mathrm{K}}$ have been determined in the crayfish giant axon while the experimental results have been obtained from the axon of the opener muscle in the walking leg of the crayfish, so there might be some discrepancy. But the point of emphasis here is that the resting membrane potential does not vary by more than $5 \mathrm{mV}$ in each case. This demonstrates that a change in $\left[\mathrm{Na}^{+}\right]_{\mathrm{o}}$ does not greatly affect the membrane potential. This was also shown earlier by Strickholm and Wallin [55], where
A

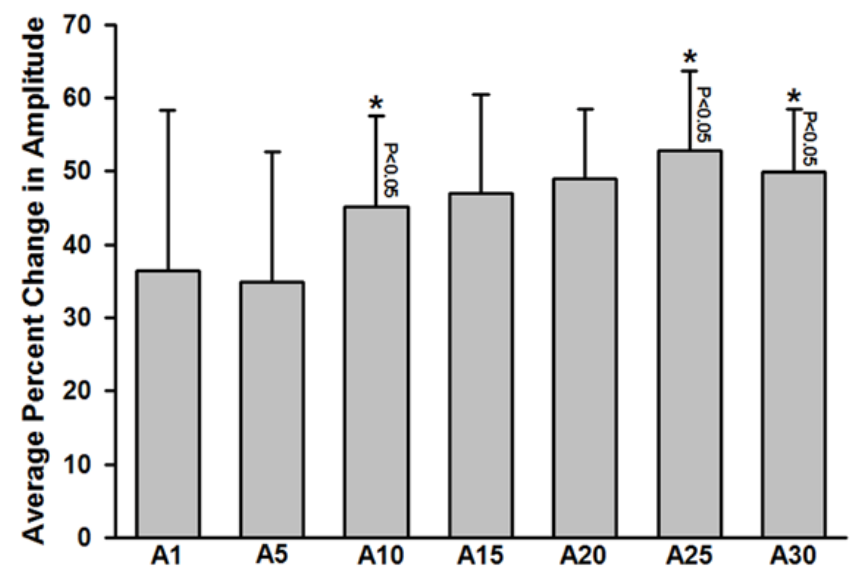

B



Fig. (6). (A) The average percent change in amplitudes recorded in the presence of the reverse NCX blocker KB-R7943. KB-R7943 causes an increase in all EPSP amplitudes $\left(P<0.05\right.$; Wilcoxon rank-sum test), but the $10^{\text {th }}, 25^{\text {th }}$ and $30^{\text {th }}$ pulses showing a significant increase as grouped data (Student's paired t-test, $\mathrm{n}=6, \mathrm{P}$ values as indicated on graph). (B) The facilitation index (FI) in presence of normal saline and saline with KB-R7943 did not significantly change. (mean \pm SEM). 
they varied $\left[\mathrm{Na}^{+}\right]_{0}$ at normal or depolarized membrane potentials and in both cases found no appreciable effect on the membrane potential occurred. The calculations used the following Goldman-Hodgkin-Katz equation:

$\mathrm{E}=(\mathrm{RT} / \mathrm{nF}) \ln \left(\mathrm{P}_{\mathrm{Na}}\left[\mathrm{Na}^{+}\right]_{\mathrm{o}}+\mathrm{P}_{\mathrm{K}}\left[\mathrm{K}^{+}\right]_{\mathrm{o}}\right) /\left(\mathrm{P}_{\mathrm{Na}}\left[\mathrm{Na}^{+}\right]_{\mathrm{i}}+\mathrm{P}_{\mathrm{K}}\left[\mathrm{K}^{+}\right]_{\mathrm{i}}\right)$

The values used were: $\mathrm{R}=8.3145 \mathrm{VCmol}^{-1} \mathrm{~K}^{-1} ; \mathrm{T}=273.15$ $+21^{\circ} \mathrm{C}=294.15 \mathrm{~K} ;\left[\mathrm{Na}^{+}\right]_{\mathrm{i}}=17.4 \mathrm{mM} ;\left[\mathrm{K}^{+}\right]_{\mathrm{i}}=256 \mathrm{mM}$; $\left[\mathrm{Na}^{+}\right]_{\mathrm{o}}=$ variable; $\left[\mathrm{K}^{\dagger}\right]_{\mathrm{o}}=5.3 \mathrm{mM} ; \mathrm{P}_{\mathrm{Na}} / \mathrm{P}_{\mathrm{K}}=1.44 \times 10^{-3}$.

\section{Action of KB-R7943 in Compromising NCX}

The reduction in $\left[\mathrm{Na}^{+}\right]_{\mathrm{o}}$ is one approach to dampen the ability of the NCX to extrude $\mathrm{Ca}^{2+}$. KB-R7943 is also used in other animal models to address a role in the reversal of NCX [57]. The action of KB-R7943 was surprising given that the EPSP amplitudes increased throughout the response train when exposed to this compound. KB-R7943 effects showed the same increasing trend in 6 out of 6 preparations for EPSP amplitudes (Fig. 6A; $P<0.05$; Wilcoxon rank-sum test). The EPSP amplitudes that were significantly different using a paired Student's $t$-test are indicated on the graph with an star. The calculated FI did not show any significant difference for any FI measures (Fig. 6B).

\section{The Effect on Transmission and STF with Compromised PMCA}

In order to block the function of the PMCA the bathing media was switched to one from a normal $\mathrm{pH} 7.2$ to one at $\mathrm{pH} 8.8$ while continuing to provide trains of stimuli. The initial EPSP within the train rapidly increased (Fig. 7A1; $\mathrm{P}<0.05$ paired Student's $t$-test). This trend was observed 6 out of 6 times for all EPSP measures within the response train $(P<0.05$; Wilcoxon rank-sum test). No significant effect was observed for the FI (Fig. 7A2). Using carboxyeosin (CE; $5 \mu \mathrm{M})$ to inhibit PMCA, as used in rats and in guinea pigs [49], did not produce the same result as raising the $\mathrm{pH}$ to 8.8 . CE produced a decrease in EPSP amplitudes for some of the preparations. Thus, an overall trend was not consistent. The
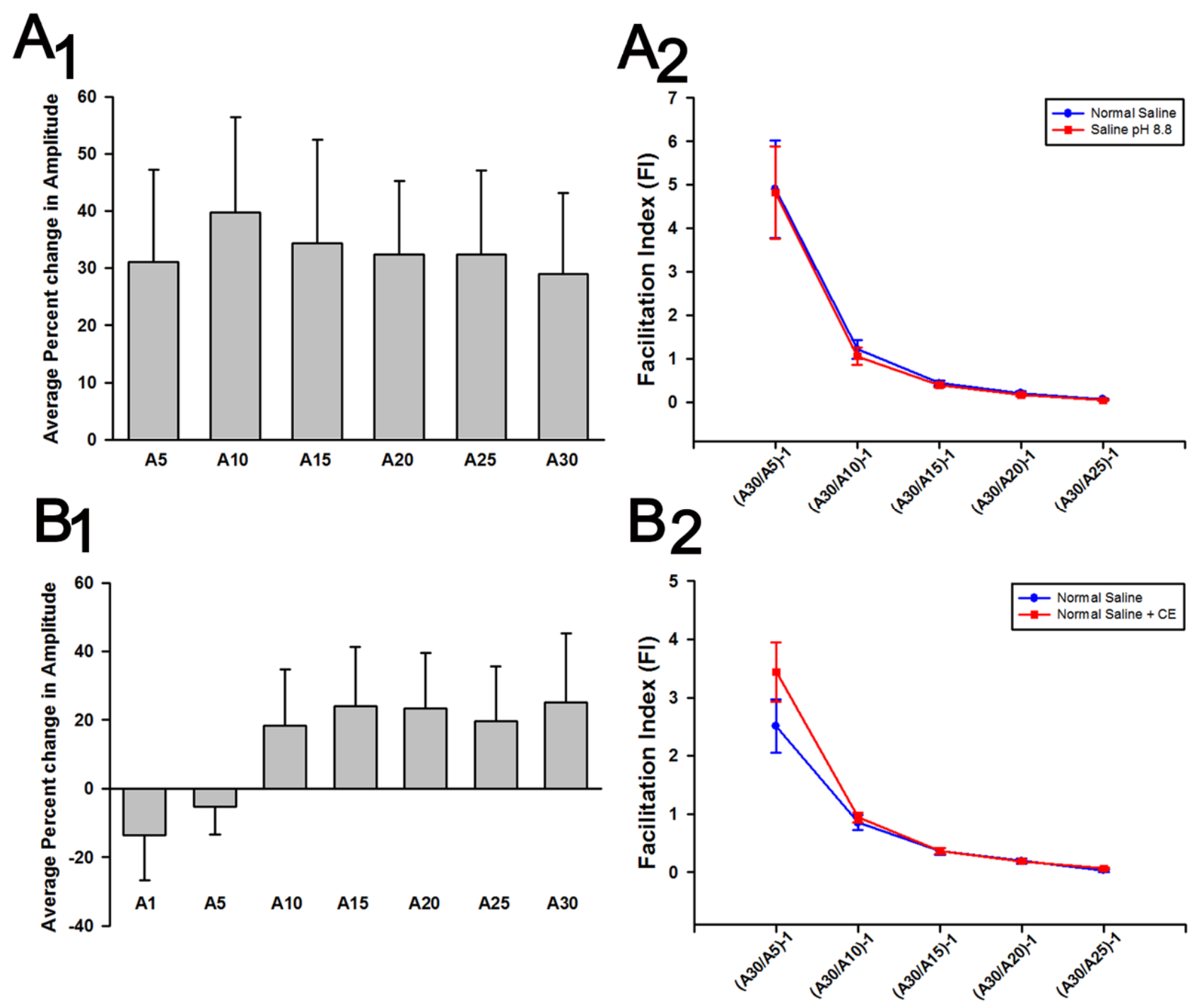

Fig. (7). The average percent change in EPSP amplitudes in the presence of saline at pH 8.8 (to inhibit the PMCA) (A1) and the PMCA inhibitory drug Carboxyeosin (CE) (B1). The results for $\mathrm{pH} 8.8$ and $\mathrm{CE}$ were not similar. The amplitudes increase for $\mathrm{pH} 8.8 \mathrm{exposure}$ $(P<0.05$, Student's paired $t$-test, $\mathrm{N}=6)$ but not for the actions of CE. $\mathbf{A} 2$ and $\mathbf{B 2}$ show the facilitation index (FI) for these two treatments $\mathrm{pH}$ 8.8 and $\mathrm{CE}$ respectively. There is no significant change in the FI with these two treatments by either parametric Student's t-test or Wilcoxon rank-sum. (mean \pm SEM). 

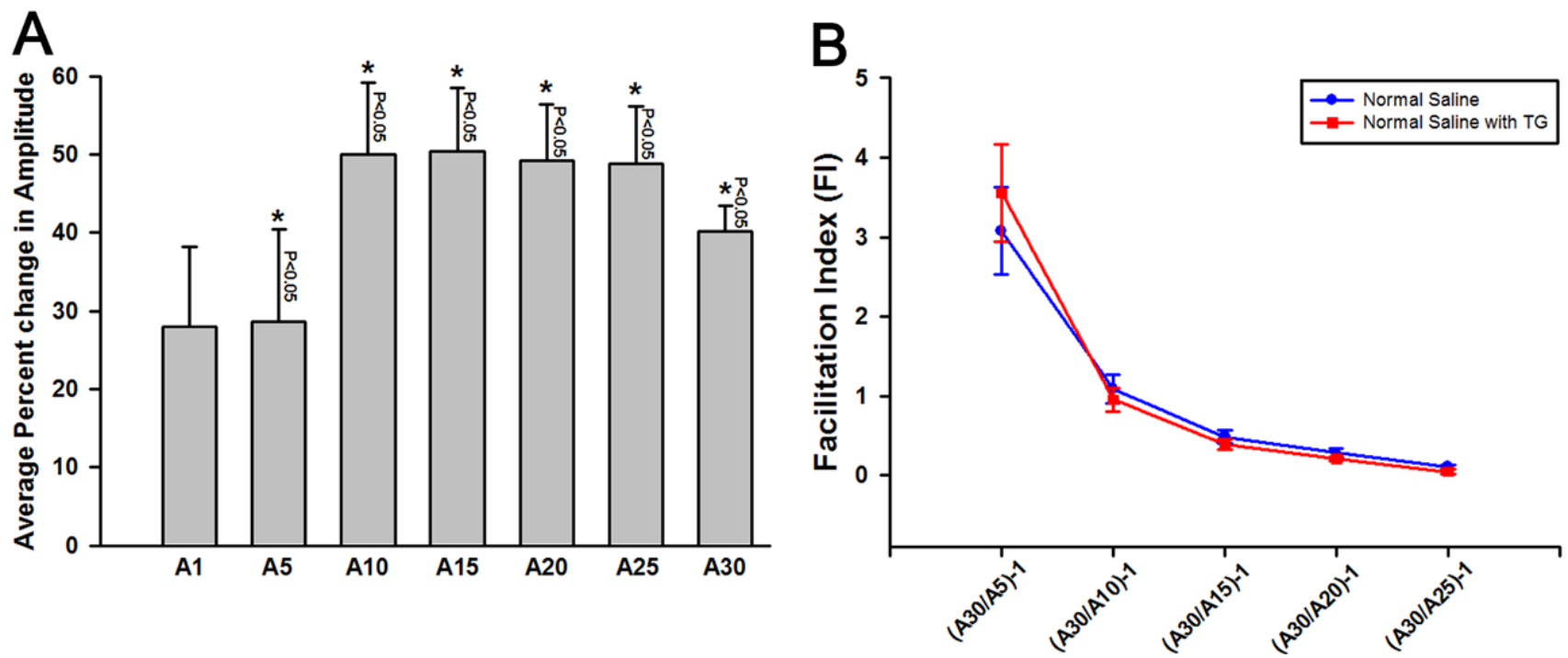

Fig. (8). (A) The percent change in EPSP amplitudes in the presence of saline with thapsigargin (TG), a SERCA inhibitor. A significant increase in amplitude of EPSPs is observed throughout the EPSP train starting with the $5^{\text {th }}$ EPSP (Student's paired $t$-test, $\mathrm{n}=6, P<0.05$ ); however, by Wilcoxon rank-sum test for each EPSP amplitude, there is a significant increase throughout the train. (B) The facilitation index (FI) in presence of TG is not significantly different from saline control. (mean \pm SEM).

percent change in the EPSP amplitudes also indicates the varied response in the action of CE (Fig. 7B1). Likewise there is no effect on FI (Fig. 7B2).

\section{The Effect on Transmission and STF with Compromised SERCA}

The $\mathrm{Ca}^{2+}$ pump on the ER (SERCA) was targeted by a pharmacological approach with application of TG $(10 \mu \mathrm{M})$. The preparations were first examined in normal saline and then incubated with $\mathrm{TG}$ for $15 \mathrm{~min}$ without nerve stimulation. The amplitude of the EPSPs increased in 6 out of 6 preparations $(P<0.05$; Wilcoxon rank-sum test) by TG for the various EPSP amplitudes measured. The percent change in the EPSP amplitudes is significant by paired
Student's $t$-test for a subset of amplitudes within the train (Fig. 8A). No significant effect was observed for the FI (Fig. 8B).

\section{The Combined Effects in Reduced Function of the NCX, PMCA and SERCA}

With use of the pharmacological approaches and ionic approaches a composite effect on the channels could be compared for synergistic or antagonist effects. Initially the effect of $\mathrm{TG}, 2 / 3 \mathrm{rds}$ reduced $\left[\mathrm{Na}^{+}\right]_{\mathrm{o}}$ and $\mathrm{pH} 8.8$ was examined. The effects on the EPSP at the start of the train were mixed among the preparations with some increasing and others showing a decrease. The percent change in the EPSP amplitudes further along in the train increased. The


Fig. (9). (A) The average percent change in EPSP amplitudes in the presence of saline with thapsigargin (TG), $2 / 3^{\text {rd }}$ reduced $\left[\mathrm{Na}^{+}\right]_{\mathrm{o}}$ and $\mathrm{pH}$ 8.8 (to inhibit all three $\mathrm{Ca}^{2+}$ related proteins; SERCA, NCX and PMCA). Inhibiting all three proteins causes and increase in the EPSP amplitudes, with pulses 10 (A10), 20 (A20) and 25 (A25) showing a significance $(P<0.05$, Student's paired $t$-test, $\mathrm{N}=6$,). (B) The facilitation index (FI) when all the three channels /changers are inhibited did not show a significant change. (mean \pm SEM). 

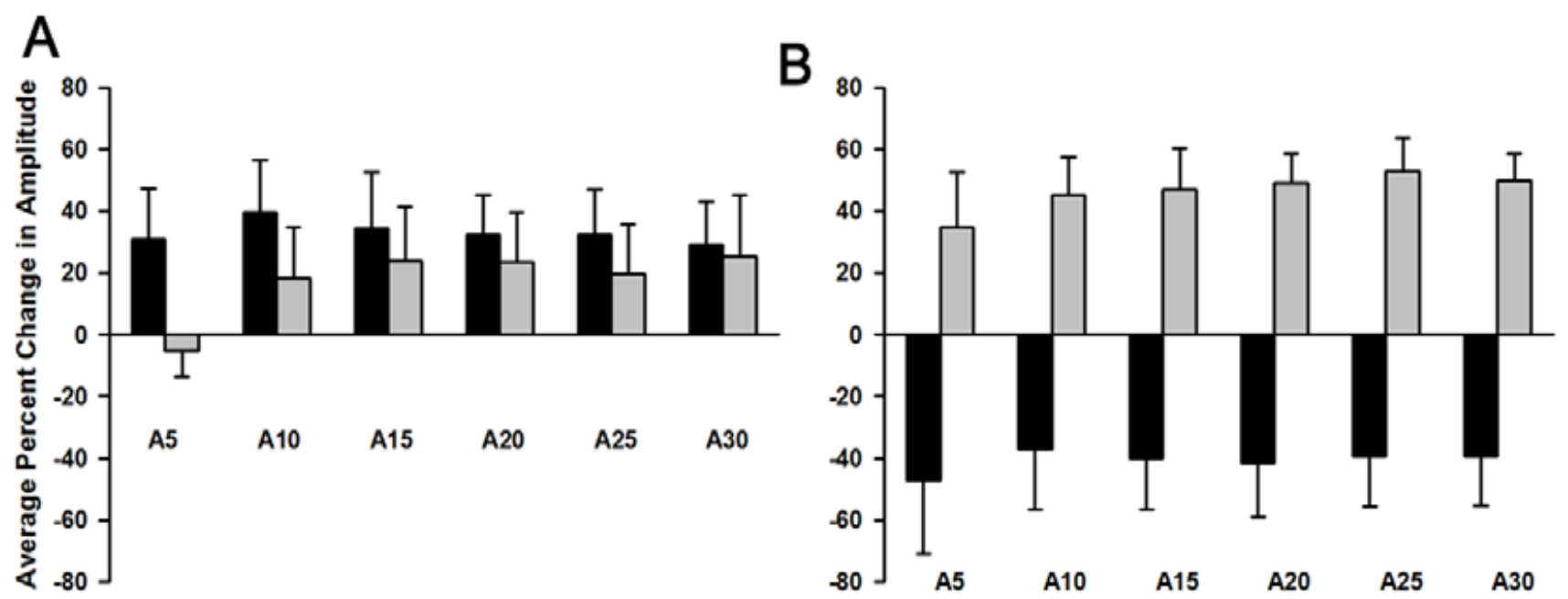

Fig. (10). (A) Comparing the average percent change in amplitude of EPSPs on blocking the PMCA by two different treatments. Both treatments show an increase in EPSP amplitudes. $\mathrm{pH}$ 8.8- Black bars; CE- Gray bars. (B) Comparing the average percent change in amplitude of EPSPs on inhibiting the NCX by two different treatments (forward and reverse NCX inhibition). $2 / 3^{\text {rd }}$ reduced $\left[\mathrm{Na}^{+}\right]_{0}-\mathrm{Black}$ bars; KB-R7943- Gray bars.

effect was significant after the $10^{\text {th }}$ EPSP within the train (Fig. 9A; $\mathrm{P}<0.05$, Student's paired $t$-test, $\mathrm{N}=6$ ). The facilitation index (FI) did not significantly change (Fig. 9B).

Comparing the effects of pharmacological agents and ionic treatments to the altered function in the NCX and PMCA are compared individually. The effect of inhibiting PMCA by $\mathrm{pH} 8.8$ treatments and exposure to CE produced somewhat similar effects in increasing the EPSP amplitudes except for the initial EPSP amplitudes of the train (Fig. (10A); replotting Fig. (7A1) and (7B1) for comparison). There is no significant difference in the effects of the two compounds using a non-paired Student's $t$-test. A paired Student's $t$-test is not valid since different preparations are being compared. To compare different approaches in targeting the NCX, one with $2 / 3$ reduced $\left[\mathrm{Na}^{+}\right]_{0}$ is compared to treatment with reverse blocker KB-R7943. The two conditions produced opposite results in the percent change of EPSP amplitudes all throughout the train (Fig. 10B).

\section{DISCUSSION}

In this study it was demonstrated that there is a steady state in the amplitude of the EPSPs during prolonged STF. This is likely due to a continuous recycling of vesicles which equates to a homeostatic balance of the $\left[\mathrm{Ca}^{2+}\right]_{i}$ during the maintained STF. Perturbing one or a combination of the SERCA, PMCA and NCX channels resulted in an alteration in the amplitudes of the EPSPs, but not necessarily FI. Also the results support the notion that all three proteins shape the extent of STF within relatively short high frequency bursts. The results support the idea that vesicular fusion is not saturated due to the lack in the ability of the terminal to dock more vesicles or that there is a limitation in synaptic area for docking during the plateau phase of STF. The plateau of transmission during the stimulus train is likely a response to steady state of influx, buffering, and efflux of calcium ions. The efflux is mostly due, in part, to the SERCA, PMCA and NCX channels. There are differences in the effects on the EPSP amplitudes depending on how the NCX is compromised. When $\left[\mathrm{Na}^{+}\right]_{0}$ is reduced by $2 / 3^{\text {rd }}$ to retard $\mathrm{Ca}^{2+}$ efflux, there is a general reduction in the EPSP amplitude, when it was expected to increase due to a build-up of $\left[\mathrm{Ca}^{2+}\right]_{\mathrm{i}}$. The application of the NCX reverse inhibitor (KB-R7943) revealed unexpected results in producing an increase in the EPSP amplitudes. The pharmacological inhibitor of the PMCA mimicked the same trend as other conventional approach of increasing $\mathrm{pH}$ to 8.8 , with both producing an increase in the EPSP amplitudes. Although $\mathrm{pH} 8.8$ was more consistent in raising the EPSP amplitudes throughout the stimulus train. The ER appears to be a major contributor in $\left[\mathrm{Ca}^{2+}\right]_{\mathrm{i}}$ handling in these motor nerve terminals since inhibition of the SERCA with TG produced the most substantial increase in EPSP amplitudes throughout the pulse train during STF. On average all of the manipulations of $\left[\mathrm{Ca}^{2+}\right]_{\mathrm{i}}$ did not have a large impact of facilitation, instead the EPSP amplitudes as a whole tended to increase or decrease in unison throughout the pulse train. This produced small changes in the ratios used to calculate FI, resulting in negligible effects on the FI.

Since the presynaptic action potential is slightly reduced $(17 \%)$ in amplitude by the lowering $\left[\mathrm{Na}^{+}\right]_{\mathrm{o}}$, this can have some effect in the duration of the depolarization remaining above the threshold for the $\mathrm{Ca}^{2+} \mathrm{v}$ channels. This might reduce enough of the $\mathrm{Ca}^{2+}$ influx during the early phase of STF as well as reduce the residual $\left[\mathrm{Ca}^{2+}\right]_{\mathrm{i}}$ which could be responsible for maintaining a lowered EPSP throughout the rest of the train. The net result did not have a significant change on facilitation. The action potential was typically in the range of 60 to $80 \mathrm{mV}$ in amplitude with approximately $74 \mathrm{mV}$ for a resting membrane potential, which for these terminals is substantially above the threshold $(-40 \mathrm{mV})$ for the P-type $\mathrm{Ca}^{2+}$ channels present $[58,59]$. Also, the potential would exceed the voltages needed to cover most all of the $\mathrm{I}_{\mathrm{Ca}}$ range for the channels as shown in the I-V curve (See Fig. 3 in Wright et al., [59]). However, when the $\left[\mathrm{Na}^{+}\right]_{\mathrm{o}}$ is reduced by $2 / 3^{\text {rd }}$ the action potential is reduced to about $66 \mathrm{mV}$ in amplitude which would then still be past the $\mathrm{I}_{\mathrm{Ca}}$ maximum but would not cover the full range of inward $\mathrm{I}_{\mathrm{Ca}}$ as shown for 


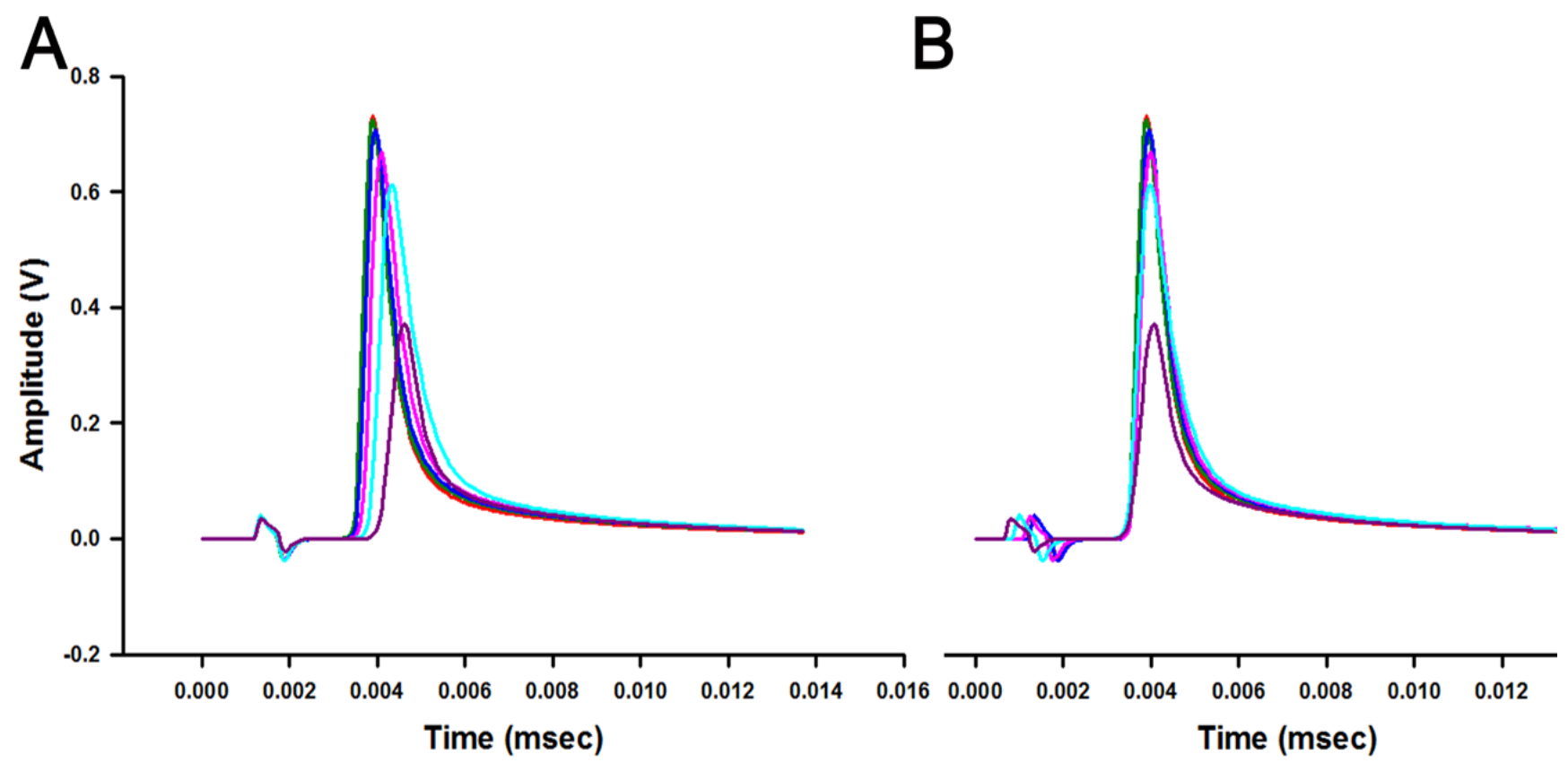

Fig. (11). (A) The superimposed action potentials, obtained in the crayfish axon from this current study, revealed a reduction in the amplitude but not in broadening over a range in $\left[\mathrm{Na}^{+}\right]_{\mathrm{o}}$. The percentage values of $\mathrm{Na}^{+}$are). $1=100 \% ; 2=80 \% ; 3=66.6 \% ; 4=50 \% ; 5=33.3 \%$ and $6=20 \%$ ). (B) The action potentials are shifted so that the initial rise is synchronized to compare the widths.

the I-V relationship. Thus, possibly the full influx of $\mathrm{Ca}^{2+}$ is compromised by the reduced action potential amplitude. However, the reduced amplitude may have impacted the width of the action potential and shortened the duration of $\mathrm{I}_{\mathrm{Ca}}$. In the superimposed action potential traces, obtained from the squid axon, with reduced $\left[\mathrm{Na}^{2+}\right]_{\mathrm{o}}$ and raised choline chloride (as used in this current study to control for osmolarity with reduced $\mathrm{Na}^{+}$) the action potential broadens (See Hodgkin and Katz, [45]; Fig. 3). Such mixed actions as a reduced amplitude but broader action potential could result in even a greater $\mathrm{Ca}^{2+}$ influx. We measured the widths of the action potential, but in the crayfish axons, with reduced $\left[\mathrm{Na}^{2+}\right]_{0}$ and raised choline chloride (Fig. 11A). Note the width is not as prolonged as in the squid axon. Therefore, the total $\mathrm{I}_{\mathrm{Ca}}$ is likely retarded slightly in our experiments with $2 / 3^{\text {rd }}$ reduced $\left[\mathrm{Na}^{2+}\right]_{\mathrm{o}}$. This is also suggestive by examining the $\mathrm{I}_{\mathrm{Ca}}$ curves in Fig. (3) of Wright et al., [59]. The slightest reduction in duration of the action potential is on a steep slope in the influx of the $\mathrm{I}_{\mathrm{Ca}}$.

It is interesting to note the similarities in the amplitudes of the action potential of the squid and crayfish axon; however, the response to lowered $\left[\mathrm{Na}^{+}\right]_{0}$ is strikingly different. The earlier report by Hodgkin and Katz [45] the RP became slightly more positive $(\sim 2-5 \mathrm{mV})$ with reduced $\left[\mathrm{Na}^{+}\right]_{\mathrm{o}}$. Even though each axon preparation had a slightly different range in resting membrane potentials as the $\left[\mathrm{Na}^{+}\right]_{\mathrm{o}}$ was manipulated the resting membrane potential became more negative with the reduction in $\left[\mathrm{Na}^{+}\right]_{0}$. Such a phenomena would incline one to suggest that there is likely a $\mathrm{I}_{\mathrm{Na}}$ leak at the normal $\left[\mathrm{Na}^{+}\right]_{\mathrm{o}}$ used and that upon reduction of $\left[\mathrm{Na}^{+}\right]_{\mathrm{o}}$ the driving gradient is reduced with the membrane potential being driven to the $\mathrm{E}_{\mathrm{K}}$ for the cell.

The slight shifts in the $\mathrm{I}_{\mathrm{Ca}}$, from altering the ionic composition of the $\mathrm{Na}^{+}$, likely produces indirect effects on STF, which complicates dissecting apart the direct effect of compromising the NCX. There may be other non-direct effects we have not accounted for in reducing $\left[\mathrm{Na}^{+}\right]_{\mathrm{o}}$, such as the possibility in altered screening potential around other ion channels which could impact the shape of the presynaptic action potential.

We used various approaches to address the role of NCX and PMCA and did not rely on a single method. The action of KB-R7943 was not expected. In growth cones of crayfish motor neurons KB-R7943 was shown to have nonspecific effects by increasing the resting $\left[\mathrm{Ca}^{2+}\right]_{\mathrm{i}}$ in normal saline [47]. If this occurred in our study, we would have expected an increase in the background $\mathrm{Ca}^{2+}$ level to have an impact on the FI but facilitation was no different before and during exposure to KB-R7943. As stated in the study by Rumpal and Lnenicka [47], KB-R7943 is known to have nonspecific effects in other systems, (blocking L-type $\mathrm{Ca}^{2+}$ channels, $\mathrm{Na}^{+}$ channels, and N-methyl-D-aspartate (NMDA) channels) [6062]. Both approaches in blocking the PMCA (raised $\mathrm{pH}$ or application of $\mathrm{CE}$ ) produced similar results. These results allow confidence for future investigations in using CE. Likewise, TG appeared to function as expected for blocking the SERCA. In this study, we used a mixture of ionic approaches to examine a combined role of the $\mathrm{Ca}^{2+}$ pumps/exchangers as we were not confident that a mixture of three pharmacological organic agents would not confound indirect effects. In addition, invertebrates have shown not to conform to all pharmacological profiles as describe for vertebrates. For example, m-chlorophenylpiperazine (m$\mathrm{CPP}$ ) which is known as a non-selective agonist to vertebrate 5-HT1 and 5-HT2 family receptors but also antagonizes 5HT2B receptors in some models, blocks $\mathrm{Na}^{+} \mathrm{V}$ in crayfish axons [43]. Paradoxical results in application to ouabain, a well known compound for blocking the $\mathrm{Na}^{+} / \mathrm{K}^{+}$-ATP pump, appeared not to have an effect on Drosophila Malpighian tubules. But this was due to the unique nature of the cells to actively excrete this organic compound [63]. Even within the vertebrate brain there are different PMCA and NCX isoforms that account for the variable responses in $\mathrm{Ca}^{2+}$ 
extrusion [26]. Thus, there might be different forms of feedback regulation or modulation of these different isoforms. Since it is not yet known which isoform exists, or even if there are multiple forms, at the crayfish motor nerve terminals we can only speculate to potential differences in regulation of these channels. It is known that in Drosophila, the NCX is inhibited by $\left[\mathrm{Ca}^{2+}\right]_{i}$, where as other NXC forms are not [64]. Also it was established that KB-R7943 is a weaker inhibitor (4-5 times) of the NCX in Drosophila (CALX1.1) than for the NCX in canines [65]. Similar activity studies needs to be performed in the crayfish model to ideally know the efficiency of pharmacological agents on the NCX, PMCA and SERCA.

Internal release of $\mathrm{Ca}^{2+}$ does not necessarily need to be localized within the terminals to have an effect within the terminals. This has been shown in hippocampal mossy fiber synapses with ryanodine receptors in axons which are involved through CICR activation leading to increases in $\mathrm{Ca}^{2+}$ load within the terminal in a activity dependent manner [66]. However, the axons and preterminals in this crayfish preparation are some distance (millimeters) from the very distal ends within the string of varicose terminals that are on the muscle surface. So the axonal alteration is unlikely to impact the terminals directly but might have a role in altering the electrochemical gradient of $\mathrm{Ca}^{2+}$ across the axonal membrane as the action potential in crayfish motor axon has a $\mathrm{Ca}^{2+}$ component [67]. Since application of 5-HT did produce a rise in intracellular $\mathrm{Ca}^{2+}$ with axons [68], there my well be ER present in axons that can modulate internal $\mathrm{Ca}^{2+}$ release.

Rumpal and Lnenicka [47] conducted a study on two types of crayfish motor neurons grown in culture and demonstrated that the that NCX exchange has a significant action in extruding large $\mathrm{Ca}^{2+}$ loads from the growth cones in both tonic and phasic motor neurons. They did compromise the NCX function by lowering $\left[\mathrm{Na}^{+}\right]_{\mathrm{o}}$ so there could be other consequences, as mentioned above, in neuronal function. However, the study also documented when the NCX was compromised that the PMCA was able to extrude the $\left[\mathrm{Ca}^{2+}\right]_{\mathrm{i}}$ sufficiently. It was also noted in the crayfish neurons that mitochondria can play a role in sequestering $\mathrm{Ca}^{2+}$ for high $\left[\mathrm{Ca}^{2+}\right]_{\mathrm{i}}$ and that the mitochondria releases it slowly as the $\left[\mathrm{Ca}^{2+}\right]_{\mathrm{i}}$ decays. In our studies, we have not addressed the role of the mitochondria's ability in sequestering $\mathrm{Ca}^{2+}$ to a role in STF. It would be of interest to compromise SERCA, NCX, PMCA as well as the other $\left[\mathrm{Ca}^{2+}\right]_{i}$ regulators (e.g., vesicle sequestering of $\mathrm{Ca}^{2+}, \mathrm{Ca}^{2+}$ binding proteins); however, it is difficult to tackle all possibilities without inducing indirect actions on vesicle docking and other ionic channels. There could be other ionic exchangers in these neurons such as the $\mathrm{K}^{+}$-dependent NCX (NCKX). This exchanger has a greater role in clearing $\mathrm{Ca}^{2+}$ in the Calyx of Held than NCX, SERCA and the PMCA [69]. The NCKX is also known to have a significant role in rat neurons [20] and in some Drosophila cells [70]. Thus, it is a challenging task to model all the factors and time domains in the multifaceted approaches occurring within the nerve terminal to regulate $\mathrm{Ca}^{2+}$.

In order to attempt a mechanistic explanation of the results obtained in this study, a relatively simple hypothetical model is shown in Fig. (12). Three sources of $\left[\mathrm{Ca}^{2+}\right]_{\mathrm{i}}$ regulation are shown for the nerve terminal being induced during STF where SERCA, PMCA and the NCX can function (Fig. 12A). Additional we are proposing that the ER could have a CICR mechanism through ryanodine receptors, which is based on previous studies from our research group [18]. We had shown with this NMJ preparation (leg opener muscle in crayfish) that injections of adenophostin-A (an IP3 analog) in the nerve terminals greatly enhances synaptic transmission. Also when the NMJ was exposed ryanodine a biphasic response occurred: At low concentration it is excitatory and high concentration it is inhibitory. Likewise, a low concentration $(1 \mu \mathrm{M})$ of caffeine enhances synaptic transmission, whereas a high concentration $(10 \mathrm{mM})$ had little effect on transmission. The varied responses and sensitivity to ryanodine and caffeine suggest a CICR and/or the presence of an IP3-receptor within the terminal [18].

If the SERCA is inactivated by thapsigargin then one would expect a rise in $\left[\mathrm{Ca}^{2+}\right]_{i}$ and thus an increase in the amplitude of the EPSPs due to more vesicles fusing (Fig. 12B). Likewise when the PMCA is dampened by high $\mathrm{pH}$ the results are fitting as for inhibiting the SERCA (Fig. 12C). Impeding the function of the NCX by reduced $\left[\mathrm{Na}^{+}\right]_{0}$ did not have the impact predicted on enhancing STF throughout the stimulus train or in increasing the EPSP amplitudes (Fig. 12D). In speculating a potential mechanism, possible with a reduction of the NCX the $\left[\mathrm{Ca}^{2+}\right]_{\mathrm{i}}$ rose to high enough levels to induced a negative feedback on the RyR and maybe even the voltage gated calcium channels leading to a subsequent decrease in $\left[\mathrm{Ca}^{2+}\right]_{\mathrm{i}}$ which resulted in fewer vesicular fusion events (as shown by the brown arrows in Fig. 12D). However, the initial $\left[\mathrm{Ca}^{2+}\right]_{\mathrm{i}}$ rise would have increased the amplitude of the EPSPs and the negative feedback would have likely been removed between the stimulus trains. An alternative mechanism, not experimentally addressed in this study, is that when extracellular $\mathrm{Na}^{+}$is reduced, intracellular $\mathrm{Na}^{+}$will also be reduced, which will reduce the activity of the mitochondrial NCX. Reducing the activity of the mitochondrial NCX will effectively enhance mitochondrial $\mathrm{Ca}^{2+}$ buffering, which could explain the reduced EPSP upon $\left[\mathrm{Na}^{+}\right]_{\mathrm{o}}$ reduction. We have not addressed the role of the mitochondria in these studies. Thus, a question mark is denoted on vesicular events within the nerve terminal in Fig (12D) during an impairment of the NCX. The KB-R7943 was used to examine the reverse mode of the NCX. If $\left[\mathrm{Na}^{+}\right]_{\mathrm{i}}$ is large enough to promote $\mathrm{Na}^{+}$efflux and $\mathrm{Ca}^{2+}$ influx then potentially inhibiting the reverse mode of NCX one might observe a reduction in the EPSP but we observed an increase. An increased $\left[\mathrm{Na}^{+}\right]_{\mathrm{i}}$ leading to opening of voltage gated calcium channels could result in enhanced vesicular fusion but this is only speculation at present. It is known that KB-R7943 can block a nonselective sodium-gated cation channel in lobsters [71]. The selectivity of KB-R7943 also needs to be examined for crayfish tissue.

If the high capacity NCX was inhibited alone and if the PMCA and the SERCA are not able to compensate quick enough during STF, the EPSP amplitudes would likely increase throughout the stimulus train and a new plateau would be reached. Thus, a new homeostatic setting in regulation for SERCA and PMCA as well as other $\mathrm{Ca}^{2+}$ buffering sources would occur. In this scenario, the high affinity, but low capacity, PMCA would have a role in maintaining the new $\mathrm{Ca}^{2+}$ equilibrium just as would the 

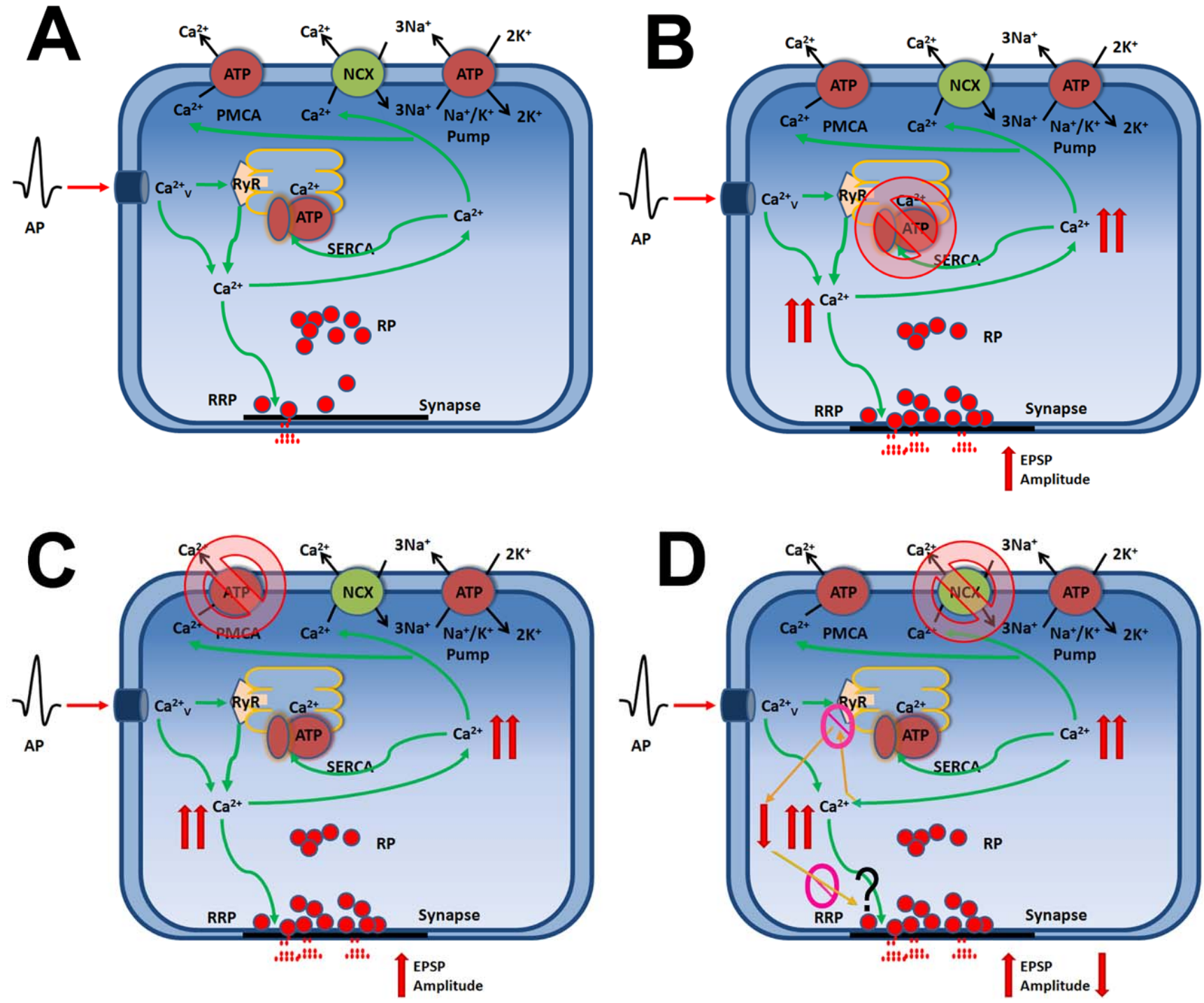

Fig. (12). Model of the presynaptic nerve terminal at the crayfish NMJ. These low-output synapses have few vesicles docked within the ready releasable pool (RRP) and many in the reserve pool (RP). Upon starting a short train of stimulations the first action potential will result in a few of vesicles to fuse and release transmitter. The subsequent nerve terminal depolarizations result in more primed vesicles and fusion; therefore, synaptic facilitation is observed by monitoring the postsynaptic muscle fiber. Reducing the function of one or the other $\mathrm{Ca}^{2+}$ buffering mechanisms results in changes in the probability of vesicle fusion.

SERCA. When all three channels are working normally, there could even be a $\mathrm{Ca}^{2+}$ induced inhibition of the $\mathrm{NCX}$, thus leaning more on the other mechanisms to maintain the synaptic balance. However, the inhibition of the SERCA or PMCA increased the amplitudes of the EPSPs early in the stimulus train and throughout the 30 pulses. This would suggest that these share a strong rapid component to bring $\left[\mathrm{Ca}^{2+}\right]_{\mathrm{i}}$ back into check. The SERCA had a larger impact on the initial facilitation when inhibited as compared to the PMCA, so likely the PMCA does not have as great of a role in rapidly buffering the rapid rise in $\left[\mathrm{Ca}^{2+}\right]_{\mathrm{i}}$ with the induction of STF. This also supports the results in the Rumpal and Lnenicka [47] study on motor nerve growth cones in which $\mathrm{Ca}^{2+}$-imaging revealed a larger $\left[\mathrm{Ca}^{2+}\right]_{\mathrm{i}}$ when the NCX was inhibited as compared to the PMCA. A more complex model would need to include various $\mathrm{Ca}^{2+}$ binding proteins with their on/off rates, potentially mitochondrial as well as vesicle buffering, other NCX/SERCA/PMCA isoforms, account for different density/amounts of the proteins, $\mathrm{Na} / \mathrm{K}$ pump and even potentially the presence of $\mathrm{KNCX}$, the types of channels $\left(\mathrm{P}-\mathrm{Ca}^{2+}{ }_{\mathrm{V}}, \mathrm{K}_{\mathrm{Ca}}^{+}\right)$present and modulation/regulation of the channels (e.g., phosphorylation, $\mathrm{Ca}^{2+}$ feedback inhibition).

The contributions of this study are furthering the understanding of three major $\left[\mathrm{Ca}^{2+}\right]_{\mathrm{i}}$ regulatory process on synaptic transmission and the impact for the onset and maintenance of STF as well as directly on vesicle dynamics [72-74]. The results indicate that NCX, PMCA and SERCA all affect the fundamental mechanisms that allow STF to occur based on the residual $\left[\mathrm{Ca}^{2+}\right]_{\mathrm{i}}$ model. Since STF is one form of memory, the alteration in regulation can lead the way to dissecting underlying mechanisms for more prolonged forms of memory or synaptic plasticity, such as long term facilitation (LTF). In fact, the same preparation used in this study is the preparation in which LTF/LTP was 
first described [8]. The information gained can also be used to address differences in high and low-output terminals not just among the opener NMJs but among other neurons (e.g., phasic and tonic NMJs) in established junctions or ones undergoing rapid organizational changes during development. The regional differences along a given terminal need to be examined for differential $\left[\mathrm{Ca}^{2+}\right]_{\mathrm{i}}$ regulation as the terminals demonstrate a developmental time course from older regions to newer ones as the terminals grow within the animal. Dysfunction in NCX, SERCA, and PMCA is known to be associated with various disease states in mammals [75]. Computationally addressing diseases and treatments, which impair synaptic transmission, may possibly be experimentally tested in electrophysiologically amenable neurons such as the crayfish opener motor nerve terminal.

\section{ACKNOWLEDGMENTS}

Dr. Garrett Sparks (an undergraduate at the time of this study) helped collect a substantial amount of data and conduct pilot experiments related to NCX function. Undergraduate Research Scholarship awarded by the Arnold and Mabel Beckman Foundation provided support for Garrett Sparks. Initially this project was, in part, supported by NSF grant IBN-0131459 (RLC). Additional funding was provided with personal funds (RLC).

\section{REFERENCES}

[1] Katz B, Miledi R. The role of calcium in neuromuscular facilitation. J Physiol 1968; 195(2): 481-92.

[2] Neher E, Sakaba T. Multiple roles of calcium ions in the regulation of neurotransmitter release. Neuron 2008; 59(6): 861-72.

[3] Xing B, Long A, Harrison DA, Cooper RL. Developmental consequences of neuromuscular junctions with reduced presynaptic calcium channel function. Synapse 2005; 57(3):132-47.

[4] Dodge FA, Rahamimoff R. Co-operative action a calcium ions in transmitter release at the neuromuscular junction. J Physiol 1967; 193(2): 419-32.

[5] Stewart BA, Atwood HL, Renger JJ, Wang J, Wu CF. Improved stability of Drosophila larval neuromuscular preparations in haemolymph-like physiological solutions. J Comp Physiol [A] 1994; 175(2): 179-91.

[6] Atwood HL, Wojtowicz JM. Short-term and long-term plasticity and physiological differentiation of crustacean motor synapses. Int Rev Neurobiol 1986; 28: 275-362.

[7] Cooper RL, Winslow J, Govind CK, Atwood HL. Synaptic structural complexity as a factor enhancing probability of calciummediated transmitter release. J Neurophysiol 1996; 75: 2451-466.

[8] Sherman RG, Atwood HL. Synaptic facilitation: long-term neuromuscular facilitation in crustaceans. Science 1971; 171(977): $1248-1250$.

[9] Atwood HL, Karunanithi S. Diversification of synaptic strength: presynaptic elements. Nat Rev Neurosci 2002; 3(7): 497-516.

[10] Catterall WA, Few AP. Calcium channel regulation and presynaptic plasticity. Neuron 2008; 59(6): 882-901.

[11] Winslow JL, Duffy SN, Charlton MP. Homosynaptic facilitation of transmitter release in crayfish is not affected by mobile calcium chelators: implications for the residual ionized calcium hypothesis from electrophysiological and computational analyses. J Neurophysiol 1994; 72(4): 1769-93.

[12] Brailoiu E, Cooper RL, Dun NJ. Sphingosine 1-phosphate enhances spontaneous transmitter release at the frog neuromuscular junction. British J Pharmacol 2002; 136: 1093-97.

[13] Berridge MJ. Elementary and global aspects of calcium signalling. J Physiol 1997; 499(Pt 2): 291-306.

[14] Berridge MJ. Unlocking the secrets of cell signaling. Annu Rev Physiol 2005; 67: 1-21.
[15] Berridge MJ, Lipp P, Bootman MD. The versatility and universality of calcium signalling. Nat Rev Mol Cell Biol 2000; 1(1): 11-21.

[16] Bouchard R, Pattarini R, Geiger JD. Presence and functional significance of presynaptic ryanodine receptors. Prog Neurobiol 2003; 69(6): 391-418.

[17] Brailoiu E, Hoard JL, Filipeanu CM, et al. Nicotinic acid adenine dinucleotide phosphate potentiates neurite outgrowth. J Biol Chem 2005; 280(7): 5646-50.

[18] Dropic AJ, Brailoiu E, Cooper RL. Presynaptic mechanism of action induced by 5 -HT in nerve terminals: Possible involvement of ryanodine and $\mathrm{IP}_{3}$ sensitive $\mathrm{Ca}^{2+}$ stores. Comp Biochem Physiol A $2005 ; 142: 355-61$.

[19] Lee SH, Rosenmund C, Schwaller B, Neher E. Differences in Ca2+ buffering properties between excitatory and inhibitory hippocampal neurons from the rat. J Physiol 2000; 525:405-18.

[20] Lee SH, Kim MH, Park KH, Earm YE, Ho WK. K+-dependent $\mathrm{Na}+/ \mathrm{Ca} 2+$ exchange is a major $\mathrm{Ca} 2+$ clearance mechanism in axon terminals of rat neurohypophysis. J Neurosci 2002; 22(16): 689199.

[21] Mattson MP, LaFerla FM, Chan SL, Leissring MA, Shepel PN, Geiger JD. Calcium signaling in the ER: Its role in neuronal plasticity and neurodegenerative disorders. Trends Neurosci 2000; 23(5): 222-9.

[22] Petersen $\mathrm{OH}$, Cancela JM. New Ca2+-releasing messengers: are they important in the nervous system? Trends Neurosci 1999; 22(11): 488-95.

[23] Liu Q, Chen B, Yankova M, Morest DK, Maryon W, Hand AR, Nonet ML, Wang ZW. Presynaptic ryanodine receptors are required for normal quantal size at the Caenorhabditis elegans neuromuscular junction. J Neurosci 2005; 25(29): 6745-54.

[24] Pezzati R, Meldolesi J, Grohovaz F. Ultra rapid calcium events in electrically stimulated frog nerve terminals. Biochem Biophys Res Commun 2001; 285(3): 724-7.

[25] Empson RM, Garside ML, Knöpfel T. Plasma membrane $\mathrm{Ca}^{2+}$ ATPase 2 contributes to short-term synapse plasticity at the parallel fiber to Purkinje neuron synapse. J Neurosci 2007; 27(14): 3753-8.

[26] Jensen TP, Filoteo AG, Knopfel T, Empson RM. Presynaptic plasma membrane $\mathrm{Ca} 2+$ ATPase isoform $2 \mathrm{a}$ regulates excitatory synaptic transmission in rat hippocampal CA3. J Physiol 2007; 579(Pt 1): 85-99.

[27] Reuter H, Porzig H. Localization and functional significance of the $\mathrm{Na}+/ \mathrm{Ca} 2+$ exchanger in presynaptic boutons of hippocampal cells in culture. Neuron 1995;15(5): 1077-84.

[28] Scheuss V, Yasuda R, Sobczyk A, Svoboda K. Nonlinear [Ca2+] signaling in dendrites and spines caused by activity-dependent depression of Ca2+ extrusion. J Neurosci 2006; 26(31): 8183-94.

[29] Fakler B, Adelman JP. Control of $\mathrm{K}(\mathrm{Ca})$ channels by calcium nano/microdomains. Neuron 2008; 59(6): 873-81.

[30] Cooper RL, Marin L, Atwood HL. Synaptic differentiation of a single motor neuron: conjoint definition of transmitter release, presynaptic calcium signals, and ultrastructure. J Neurosci 1995; 15: 4209-22.

[31] Cooper RL, Hampson D, Atwood HL. Synaptotagmin-like expression in the motor nerve terminals of crayfish. Brain Res 1995; 703: 214-16.

[32] Cooper RL, Harrington C, Marin L, Atwood HL. Quantal release at visualized terminals of crayfish motor axon: Intraterminal and regional differences. J Comp Neurol 1996; 375: 583-600.

[33] Atwood HL, Cooper RL. Functional and structural parallels in crustaceans and Drosophila neuromuscular systems. Am Zool 1995; 35: 556- 65 .

[34] Atwood HL, Cooper RL. Assessing ultrastructure of crustacean and insect neuromuscular junctions. J Neurosci Meth 1996; 69: 51-58.

[35] Atwood HL, Cooper RL. Synaptic diversity and differentiation: Crustacean neuromuscular junctions. Invertebrate Neurosci 1996; 1: 291-307.

[36] Cooper RL, Stewart BA, Wojtowicz JM, Wang S, Atwood HL. Quantal measurement and analysis methods compared for crayfish and Drosophila neuromuscular junctions and rat hippocampus. J Neurosci Methods 1995; 61: 67-78.

[37] Johnstone AFM, Viele K, Cooper RL. Structure/Function assessment of crayfish neuromuscular junctions: Stem regions. Synapse 2010; In press.

[38] Wojtowicz JM, Atwood HL. Correlation of presynaptic and postsynaptic events during establishment of long-term facilitation 
at crayfish neuromuscular junction. J Neurophysiol 1985; 54(2): 220-30.

[39] Crider ME, Cooper RL. The importance of the stimulation paradigm in determining facilitation and effects of neuromodulation. Brain Res 1999; 842: 324-31.

[40] Crider ME, Cooper RL. Differentially facilitation of high- and lowoutput nerve terminals from a single motor neuron. J Appl Physiol 2000; 88: 987-96.

[41] Bradacs H, Cooper RL, Msghina M, Atwood HL. Differential physiology and morphology of phasic and tonic motor axons in a crayfish limb extensor muscle. J Exp Biol 1997; 200: 677-91.

[42] Cooper RL, Dönmezer A, Shearer J. Intrinsic differences in sensitivity to 5-HT between high- and low-output terminals innervating the same target. Neurosci Res 2003; 45: 163-72.

[43] Sparks GM, Brailoiu E, Brailoiu C, Dun NJ, Tabor J, Cooper RL. Effects of $\mathrm{m}$-CPP in altering neuronal function: Blocking depolarization in invertebrate motor \& sensory neurons but exciting rat sensory neuron. Brain Res 2003; 969(1-2): 14-26.

[44] Desai-Shah M, Cooper RL. Different mechanisms of Ca2+ regulation that influence synaptic transmission: Comparison between crayfish and Drosophila neuromuscular junctions. Synapse 2009; 63: 1100-21.

[45] Hodgkin AL, Katz B. The effect of sodium ions on the electrical activity of giant axon of the squid. J Physiol 1949; 108: 37-77.

[46] Cooper AS, Cooper RL. Historical view and physiological demonstration of synaptic transmission at the crayfish opener muscle. J Visual Exp (JoVE) 2009; 33. http://www.jove.com/index/details.stp?id=1595; doi: $10.3791 / 1595$.

[47] Rumpal N, Lnenicka GA. Ca2+ clearance at growth cones produced by crayfish motor axons in an explant culture. J Neurophysiol 2003; 89(6): 3225-34

[48] Satoh H, Ginsburg KS, Qing K, Terada H, Hayashi H, Bers DM. KB-R7943 block of $\mathrm{Ca}(2+)$ influx via $\mathrm{Na}(+) / \mathrm{Ca}(2+)$ exchange does not alter twitches or glycoside inotropy but prevents $\mathrm{Ca}(2+)$ overload in rat ventricular myocytes. Circulation 2000; 101(12): 1441-46.

[49] Mackiewicz U, Lewartowski B. Temperature dependent contribution of $\mathrm{Ca} 2+$ transporters to relaxation in cardiac myocytes: Important role of sarcolemmal Ca2+-ATPase. J Physiol Pharmacol 2006; 57(1): 3-15.

[50] Dudel J, Kuffler SW. Mechanism of facilitation at the crayfish neuromuscular junction. J Physiol 1961; 155: 530-42.

[51] Dudel J. Graded or all-or-nothing release of transmitter quanta by local depolarizations of nerve terminals on crayfish muscle? Pflugers Arch 1983; 398(2): 155-64.

[52] Sparks G, Cooper RL. 5-HT offsets homeostasis of synaptic transmission during short-term facilitation. J Appl Physiol 2004; 96: 1681-90.

[53] Mykles DL, Medler SA, Koenders A, Cooper RL. Myofibrillar protein isoform expression is correlated with synaptic efficacy in slow fibres of the claw and leg opener muscles of crayfish and lobster. J Exp Biol 2002; 205(4): 513-22.

[54] LaFramboise W, Griffis B, Bonner P, Warren W, Scalise D, Guthrie RD, Cooper RL. Muscle type-specific myosin isoforms in crustacean muscles. J Exp Zool 2000; 286: 36-48.

[55] Strickholm A, Wallin BG. Relative ion permeabilities in the crayfish giant axon determined from rapid external ion changes. J Gen Physiol 1967; 50(7): 1929-53.

[56] Strickholm A. Ionic permeability of $\mathrm{K}, \mathrm{Na}$, and $\mathrm{Cl}$ in potassiumdepolarized nerve. Dependency on $\mathrm{pH}$, cooperative effects, and action of tetrodotoxin. Biophys J 1981; 35(3): 677-97.

[57] Wu F, Wei GZ, Li WJ, Liu B, Zhou JJ, Wang HC, Gao F. Low extracellular $\mathrm{K}(+)$ increases intracellular $\mathrm{Ca}(2+)$ oscillation and injury by activating the reverse mode $\mathrm{Na}(+)-\mathrm{Ca}(2+)$ exchanger and inhibiting the $\mathrm{Na}(+), \mathrm{K}(+)$ ATPase in rat cardiomyocytes. Int $\mathrm{J}$ Cardiol 2010; 140(2):161-8. PMID: 19059659

[58] Araque A, Clarac F, Buño W. P-type Ca2+ channels mediate excitatory and inhibitory synaptic transmitter release in crayfish muscle. Proc Natl Acad Sci USA 1994; 91(10): 4224-8.

[59] Wright SN, Brodwick MS, Bittner GD. Calcium currents, transmitter release and facilitation of release at voltage-clamped crayfish nerve terminals. J Physiol 1996; 496: 363-78.

[60] Arakawa N, Sakaue M, Yokoyama I, Hashimoto H, Koyama Y, Baba A, Matsuda T. KB-R7943 inhibits store-operated Ca2+ entry in cultured neurons and astrocytes. Biochem Biophys Res Commun 2000; 279: 354-7.

[61] Matsuda T, Arakawa N, Takuma K, et al. SEA0400, a novel and selective inhibitor of the $\mathrm{Na}+/ \mathrm{Ca} 2+$ exchanger, attenuates reperfusion injury in the in vitro and in vivo cerebral ischemic models. J Pharmacol Exp Ther 2001; 298: 249-56.

[62] Sobolevsky AI, Khodorov BI. Blockade of NMDA channels in acutely isolated rat hippocampal neurons by the $\mathrm{Na}+/ \mathrm{Ca} 2+$ exchange inhibitor KB-R7943. Neuropharmacology 1999; 38: $1235-42$

[63] Torrie LS, Radford JC, Southall TD, et al. Resolution of the insect ouabain paradox. Proc Natl Acad Sci USA 2004; 101(37): 1368993.

[64] Hryshko LV, Matsuoka S, Nicoll DA, et al. Anomalous regulation of the Drosophila $\mathrm{Na}(+)-\mathrm{Ca} 2+$ exchanger by $\mathrm{Ca} 2+$. J Gen Physiol 1996; 108(1): 67-74.

[65] Isaac MR, Elias CL, Lee HD, Omelchenko A, Hnatowich M, Hryshko LV. Inhibition of the Drosophila $\mathrm{Na}+/ \mathrm{Ca} 2)$ exchanger, CALX1.1, by KB-R7943. Ann NY Acad Sci 2002; 976: 543-545.

[66] Shimizu H, Fukaya M, Yamasaki M, Watanabe M, Manabe T, Kamiya $\mathrm{H}$. Use-dependent amplification of presynaptic $\mathrm{Ca} 2+$ signaling by axonal ryanodine receptors at the hippocampal mossy fiber synapse. Proc Natl Acad Sci USA 2008;105(33):11998-2003.

[67] Atwood HL. Membrane physiology of crustacean neurons. In Podesta RB, Ed. Membrane physiology of invertebrates; New York, Marcel Dekker, Inc. 1982; pp.341-407.

[68] Delaney K, Tank DW, Zucker RS. Presynaptic calcium and serotonin-mediated enhancement of transmitter release at crayfish neuromuscular junction. J Neurosci 1991;11:2631-2643.

[69] Kim MH, Korogod N, Schneggenburger R, Ho WK, Lee SH. Interplay between $\mathrm{Na}+/ \mathrm{Ca} 2+$ exchangers and mitochondria in $\mathrm{Ca} 2+$ clearance at the calyx of Held. J Neurosci 2005; 25(26): 6057-65.

[70] Winkfein RJ, Pearson B, Ward R, Szerencsei RT, Colley NJ, Schnetkamp PP. Molecular characterization, functional expression and tissue distribution of a second NCKX Na+/Ca2+ -K+ exchanger from Drosophila. Cell Calcium 2004; 36(2): 147-55.

[71] Pezier A, Bobkov YV, Ache BW. The Na+/Ca2+ exchanger inhibitor, KB-R7943, blocks a nonselective cation channel implicated in chemosensory transduction. J Neurophysiol 2009; 101(3):1151-1159.

[72] Awatramani GB, Price GD, Trussell LO. Modulation of transmitter release by presynaptic resting potential and background calcium levels. Neuron 2005; 48(1): 109-21.

[73] Hosoi N, Sakaba T, Neher E. Quantitative analysis of calciumdependent vesicle recruitment and its functional role at the calyx of Held synapse. J Neurosci 2007; 27(52): 14286-98.

[74] Lee JS, Kim MH, Ho WK, Lee SH. Presynaptic release probability and readily releasable pool size are regulated by two independent mechanisms during posttetanic potentiation at the calyx of Held synapse. J Neurosci 2008; 28(32): 7945-53.

[75] Mata AM, Sepulveda MR. Calcium pumps in the central nervous system. Brain Res Rev 2005; 49(2): 398-405. 